\title{
EL APROVECHAMIENTO DE TURBIAS EN SAN VICENTE DEL RASPEIG (ALICANTE) COMO EJEMPLO DE SISTEMA DE RIEGO TRADICIONAL Y SOSTENIBLE ${ }^{1}$
}

\author{
Álvaro Francisco Morote Seguido \\ Instituto Interuniversitario de Geografía \\ Universidad de Alicante
}

\section{RESUMEN}

En San Vicente del Raspeig, el sistema de riego tradicional, al igual que en otras partes del sureste peninsular, ha sido el aprovechamiento de turbias, también conocido como práctica de boqueras. Este sistema aprovechaba las escorrentías tras episodios de lluvias, para regar, abonar los campos, llenar cisternas y aljibes. Esta modalidad de aportación de aguas esporádicas fue abandonándose progresivamente durante la primera mitad del siglo XX con la implantación de nuevas técnicas agrícolas y la llegada de caudales de otras regiones que garantizaban un volumen de agua regular durante todo el año. Actualmente, el abandono de las antiguas áreas en las que se practicaba este aprovechamiento y la ocupación de éstas a favor de usos residenciales, ha favorecido la génesis de una serie de problemáticas ambientales y territoriales, que estas técnicas minimizaban.

Palabras clave: aprovechamiento de turbias, escorrentía, abandono agrícola, sureste peninsular, sostenibilidad.

\section{ABSTRACT}

The use of muddy water in San Vicente del Raspeig (Alicante) as an example of traditional and sustainable irrigation system

In San Vicente del Raspeig, the traditional irrigation system, as in other parts of the southeast of Spain, has been the use of muddy water. This system took advantage runoff after rainfall events to water, to fertilize the crops and filling tanks and cisterns. This type of sporadic water provision was abandoning progressively during the middle of the twentieth century with the introduction of new agricultural techniques and the arrival of water supplies from others regions that guaranteed a full flow throughout the year. Nowadays, the abandonment of areas that this system was practiced and its occupation for residential uses have generated the spread of environmental and territorial problems that this traditional irrigation system minimized.

Key words: use of muddy water, runoff, agricultural abandonment, southeast of Spain, sustainability.

\section{INTRODUCCIÓN}

El aprovechamiento de turbias o práctica de boqueras ha sido la técnica tradicional utilizada para regar los cultivos de secano en San Vicente del Raspeig hasta que se produjo la introducción de nuevos sistemas

Contacto: alvaro.morote@ua.es

1 Este artículo es resultado de la concesión de una beca pre-doctoral de Formación de Profesorado Universitario del Programa Nacional de Investigación Científica, Desarrollo e Innovación Tecnológica (FPU) y se inserta en el Proyecto de Investigación "Urbanización y metabolismo hídrico en el litoral de Alicante: análisis de tendencias para el periodo 2000-2010" (CSO2012-36997-CO2-02) financiado por el Ministerio de Ciencia y Tecnología. 
como, por ejemplo, la explotación de aguas subterráneas y la llegada de caudales de otras aéreas. Esta práctica consistía en el aprovechamiento del agua de la lluvia que circulaba por las ramblas y barrancos, de las escorrentías de las laderas, etc., para posteriormente ser canalizada hasta los campos de cultivo, o bien, para almacenarse en aljibes o cisternas para uso doméstico. Para ello, se instalaba en el lecho de las rambla una presa generalmente de mampostería que provocaba la interceptación de una parte de la arroyada, la cual era desviada hacia un canal lateral que se denomina "boquera" (Morales, 1969). Una vez se había extraído el caudal del cauce fluvial, se distribuía mediante una red cuya complejidad dependía de la importancia de la superficie a regar.

Este sistema se reduce prácticamente a ámbitos áridos y semiáridos del sureste de la península ibérica, los cuales apenas ocupan el 2,5\% del territorio peninsular (Mondéjar, 2009). La mayoría de estos aprovechamientos se han llevado a cabo por parte del ser humano con carácter tradicional, de manera que los conocimientos de estas prácticas han sido transmitidas generación tras generación a través de la fuente oral. La utilización de boqueras en el sureste peninsular ya fue empleada de manera difusa por las poblaciones de la cultura argárica (1900-1300 AC) y posteriormente por los romanos (López, 2003). Con la llegada de los musulmanes la técnica fue mejorada con la intensificación y perfeccionamiento de su uso. En el siglo XVIII se produjo una mejora e incremento de la intensidad de este sistema debido al progreso de la agricultura. El empleo de nuevas técnicas o la sustitución de aquéllas que eran inadecuadas permitió aumentar la producción agrícola (Hernández, 1994). Estas mejoras dieron lugar a un aumento y mejora de los aprovechamientos de turbias, gracias a la creación de grandes diques de derivación capaces de aprovechar al máximo los caudales posibles como, por ejemplo, en las localidades vecinas de Muchamiel, San Juan y El Campello con sus respectivos azudes en el Río Montnegre. Las boqueras representaron en estas tierras el sistema más extendido para la conservación del suelo y agua, que son éstos, dos elementos escasos e imprescindibles para el desarrollo de la agricultura de secano (Box, 1990). Este sistema era peligroso ya que los campesinos tenían que ir hacia las ramblas y barrancos para regular el caudal, abrir los portones instalados en las "bocas" y laborioso, al tener que reparar los desperfectos de la boquera y del dique causados por la fuerza e intensidad de la avenida a cualquier hora del día tras un episodio de lluvias intensas.

El término municipal de San Vicente del Raspeig (provincia de Alicante) se asienta sobre un glacis cuaternario que desciende de la parte más montañosa de los relieves del Maigmó, el Ventós y la Escobella. Es una tierra de secano, un plà de botxes (de malas hierbas) (Canals, 2012), en el que no hay ningún curso de agua permanente, por lo tanto los agricultores tenían que aprovechar el agua de la lluvia de la manera más eficaz posible e incluso instalar sus campos de cultivo en las mismas ramblas. El municipio se enmarca dentro de los ecosistemas semiáridos españoles que se caracterizan por la escasez de precipitaciones. Los valores medios de precipitación anual rondan para el observatorio meteorológico más cercano situado en Ciudad Jardín (Alicante), los 356,8 mm., (AEMET), pero caracterizados por un carácter extremo, ya que las precipitaciones son muy irregulares porque fácilmente puede llover más de la mitad de lo que precipita en un año en tan sólo unas horas. Significativa es la frase del profesor Gil Olcina, quien afirma que "en la fachada Este de España no sabe llover, ya que en estas tierras nos encontramos con duras y prolongadas sequías con esporádicos diluvios, copiosos e intensos" (Gil y Rico, 2007: 12). Por lo tanto, se daba el caso de que en algunos años la práctica de boqueras no se llevaba a cabo porque no llovía, pero también podría suceder ante una riada, que destrozará o colmatara parte de este sistema ya que el agua circulaba acompañada de barro, piedras, cañizo, etc., con lo que hacía muy difícil su práctica. En algunas zonas donde los aportes hídricos durante todo el año estaban casi garantizados como, por ejemplo, el caso de la Vega Baja con el Río Segura, no tenían que preocuparse y salir al campo cuando llovía, cosa que era indispensable para los agricultores de San Vicente del Raspeig.

El barranco más importante de la localidad es la Rambla del Rambuchar, también conocida históricamente como Desembuchar (significado de sacar agua de la rambla, es decir "práctica de boqueras") o Barranco de las Boqueras según se cita en el mapa de Coello de 1859. Destacan algunos de sus afluentes donde también se practicaban las boqueras como, por ejemplo, la Rambla del Cardinxalet o la Rambla del Sabinar. Éstas se llevaban a cabo también en otras cuencas como la de la Rambla del 
Juncaret y sus afluentes. Un ejemplo es El Barranquet, que es como se le conoce al Barranco de Orgegia a su paso por San Vicente del Raspeig, al igual que un importante número de torrentes y cañadas que se extienden por las partidas de Canastell y El Raspeig.

Las primeras referencias escritas que se encuentran relacionadas con la práctica de boqueras son muy antiguas y se hallan en las normas reguladoras sobre su uso y buena gestión. El primer texto que hace referencia a la utilización de las aguas de avenida y su forma de aprovecharla es el Fuero Juzgo o Libro de los Jueces (fecha aproximada entorno al año 645), donde se indica que: "nengun omne debe encerrar el rio por toller la pro a todos los otros, é facerla suya; mas puede facer seto fasta medio del rio, alli o es el agua mas fuerte, é que la otra meatad finque libre para la pro de los omnes" (Morales et al., 1989). También en la obra del siglo XIII, El Código de las Siete Partidas (1256-1263) se hace mención al modo de aprovechar las aguas de escorrentía difusa: "El dueño de la heredad superior puede retener en ellas las aguas de lluvias otras semejantes para darles el destino que más le acomode, aunque el dueño de la heredad inferior las hubiere aprovechado siempre y salvo que tuviese título constitutivo que le diese el derecho a tomarlas al salir del predio más alto" (Mondéjar, 2009). Además, hay que mencionar a las normativas reguladoras locales históricas como, por ejemplo, las Ordenanzas del Campo y la Huerta de Murcia Aprobada por Carlos II (1625), las Ordenanzas y Privilegios de la Muy Noble y Leal Ciudad de Lorca (1763) o el Reglamento para el aprovechamiento de las aguas de Riego de la Huerta de Alicante (1849), que hacían especialmente referencia al aprovechamiento de las aguas de avenida por ser este caudal de libre disposición (Morales et al., 1989). También tienen en cuenta los aprovechamientos de turbias las primeras disposiciones legales que se dictan en España a finales siglo XIX como, por ejemplo, el Real Decreto de abril de 1860 (previo a la primera Ley de Aguas de 2 de agosto de 1866) o la Ley de Aguas de 1879, en que se permite la construcción de aljibes en terrenos públicos, al igual que "ribazos", "malecones" o "paredes" y que éstas no impidan el curso total de las aguas para que puedan ser aprovechadas eventualmente (Mondéjar, 2009).

En las tierras de San Vicente del Raspeig la primera referencia escrita sobre la práctica de boqueras se encuentra en los protocolos notariales entre 1643 y 1650 donde se indica: "En la partida del Raspeig, cuando por causa de alguna avenida de envergadura se rompía la boquera para el riego, el arreglo corría siempre por cuenta del arrendatario" (Alberola, 1984:285). Destacan las descripciones de los aprovechamientos de turbias en las tierras colindantes con la localidad vecina de Agost llevadas a cabo por Antonio José Cavanilles en su obra "Obervaciones sobre la Historia Natural, Geografía, Agricultura, Población y Frutos del Reyno de Valencia" (1795-1797): "Quien ignore ser suma la escasez de agua en aquella parte del reyno, y que à veces un solo riego basta para asegurar y aumentar las cosechas, extrañará ver salir los labradores hácia sus haciendas quando empieza á tronar, ó amenaza alguna tempestad: los truenos, que en otras partes del reyno sirven de señal para retirarse á sus habitantes lo son aquí para desemparalas y salir en busca de las aguas y deseado riego: se fecundan entonces los olivos, higueras, almendros, viñas y algarrobos: y el suelo entero se mejora con el cieno que traen las aguas" (Cavanilles, 1797:524).

El propio topónimo "El Raspeig" hace mención a la práctica de boqueras, ya que entre las diferentes hipótesis sobre su posible significado, "El Raspeig" derivaría de "Ras de la pixera" (pixera o peixera es boquera en catalán), es decir, una llanura elevada (ras) donde se practica el riego de boqueras (Aura et al., 2006). Según esta teoría este sistema se llegó a realizar como mínimo en San Vicente del Raspeig en el siglo XVI, ya que este topónimo aparece descrito por primera vez en un mapa de 1580 del ingeniero Cristóbal Antonelli con motivo de la dirección de las obras de construcción del Pantano de Tibi (1580-1594) para regar las huertas del término municipal de Alicante. También se encuentran otros topónimos relacionados con esta práctica en el término municipal como, por ejemplo, la partida de Boqueres, La Boquera, el Camino de la Boquera, las Casas de Boqueras, etc.

Por lo tanto, el aprovechamiento de turbias en esta localidad ha sido históricamente un elemento clave para el desarrollo de la actividad agrícola, que tuvo su mayor auge en los siglos XVIII-XIX, hasta la utilización de norias y pozos artesianos de finales del siglo XIX. Hasta entonces, el secano era el paisaje predominante en todo el término municipal, donde los principales cultivos eran el almendro, el algarrobo, el olivo, el cereal, el viñedo y la barrilla. En el siglo XVIII la mejora de la práctica de 
boqueras y el incremento del cultivo de la barrilla impulsó un aumento de la población dispersa por todo el término municipal en caseríos, al igual que la roturación de nuevas tierras hasta las cotas más altas. Este proceso llamado "Hambre de tierras" (Hernández, 1997) consistía en aumentar la producción mediante el incremento de la superficie cultivada, ya que la tecnología y técnicas disponibles en aquella época eran precarias. Posteriormente con las nuevas técnicas agrícolas y de regadío, la posibilidad de disponer de caudales foráneos, sumado al abandono de la actividad agrícola por su escasa rentabilidad en estas tierras, han sido las principales causas del continúo abandono de buena parte de los aprovechamiento de turbias.

\section{OBJETIVOS Y METODOLOGÍA}

El objetivo de este estudio es conocer las características principales de los aprovechamientos de turbias en San Vicente del Raspeig, la importancia que tuvo en el pasado, identificar las antiguas áreas regadas y su extensión, al igual que analizar el estado actual, la problemática y repercusión ambiental que suponía este práctica.

Para su consecución, el primer paso para la elaboración de esta investigación desde el punto de vista metodológico ha sido una búsqueda bibliográfica relacionada con los estudios sobre los aprovechamientos de turbias en el sureste peninsular. Ello ha permitido establecer el estado de la cuestión, es decir, quienes han analizado esta temática y las líneas de investigación llevadas a cabo. Entre las publicaciones más representativas destacan las de Antonio López Gómez (1951, 1973, 1974, 1976, 1996), Alfredo Morales Gil (1969, 1983, 1984, 1986, 1989), Antonio Gil Olcina (1971, 1975, 1993, 2004), José María Gómez Espín (1996, 2007, 2008, 2012), Encarnación Gil Meseguer (2006, 2007, 2008, 2012), Margarita Box Amorós (1983, 1986, 1989, 1990, 1995), Concepción Bru Ronda (1983, 1984), Juan Antonio Marco Molina (1988, 1989, 1995), María Hernández Hernández (1994, 1997, 2010), Alfredo Pérez Morales (2010, 2012), José Manuel Mondéjar Sánchez (2003, 2009), entre otros. Una mención específica requiere la Tesis Doctoral de José Manuel Mondéjar Sánchez, "El riego de boqueras: una técnica hidraúlica para la gestión ambiental de territorios semiáridos y lucha contra la desertificación. Aprovechamientos tradicionales de aguas de escorrentía en las cuencas de la comarca de l'Alacantí", dado el ámbito territorial de estudio. En ella, se analiza la práctica de boqueras en la comarca de l'Alacantí, siendo San Vicente del Raspeig uno de los municipios que destaca por la presencia de este sistema y en el que las antiguas áreas regadas han sido ocupadas por suelos urbanos-residenciales.

La segunda fase metodológica ha sido la identificación y catalogación de todas las boqueras de San Vicente del Raspeig, analizando su estado de conservación, su tipología constructiva, el tipo de escorrentía aprovechada (difusa o concentrada), la superficie regada, sus repercusiones territoriales actuales, etc. Para ello se han consultado varias fuentes, entre ellas las fotografías aéreas del vuelo americano de 1956 y la fotografía aérea actual (google maps) cuya información se ha contrastado con el trabajo de campo. Además, se han revisado los Bosquejos Planimétricos de 1898 del municipio, con la finalidad de poder observar los topónimos de finales del siglo XIX relacionados con las boqueras. Con la consulta de varias fuentes documentales se trataba de identificar las áreas beneficiadas con este sistema de derivación de agua, pero también su estado actual para, posteriormente, tratar de señalar relaciones entre estas técnicas y determinados problemas ambientales que acontecen en esos espacios.

La restitución fotogramétrica ha permitido la realización de un análisis cartográfico mediante un Sistema de Información Geográfica (SIG), donde queda recogido todo el sistema de boqueras, al igual que una aproximación de la antigua superficie regada a principios del siglo XX. Se ha elegido esta fecha, porque hasta este momento el único aporte hídrico extra a los cultivos eran los derivados de los aprovechamientos de turbias, ya que no es hasta 1920 cuando se produce la entrada del regadío moderno con la denominada "Sociedad de Riegos de la Huerta de Alicante", que transportaba agua desde El Zarizejo (Villena) hasta estas tierras (Canals, 2012). La superficie cultivada estudiada ha sido la obtenida a partir del Censo Agrario de Figueras Pacheco de 1908, ya que en esa fecha los cultivos predominantes en San Vicente del Raspeig eran los de secano (el 95\%), por lo tanto el principal sistema para aportar agua a los cultivos era la práctica de boqueras. 


\section{EL APROVECHAMIENTO DE TURBIAS EN SAN VICENTE DEL RASPEIG}

En San Vicente del Raspeig, al igual que en otros sectores del sureste peninsular, el conocimiento del territorio era tal que la sociedad del momento sabía cómo aprovechar los escasos recursos que les ofrecía el medio. Los agricultores tenían que conseguir el máximo caudal de las aguas de escorrentía de las lluvias ( $\tan$ escasas e irregulares en este ámbito) para poder regar con un aporte hídrico extra los cultivos de secano de la época, además de crear nuevos suelos, fertilizar las tierras, etc. Este aprovechamiento de escorrentías depende de la naturaleza del agua a aprovechar que, como analizó Mondéjar (2009), las clasificó diferenciando entre escorrentías de aguas difusas o concentradas. Teniendo en cuenta que el total de la superficie del término municipal son $39,34 \mathrm{~km}^{2}$ (3.934 ha.), la superficie total donde se practicaba la técnica de las boqueras a principios del siglo XX era aproximadamente de 1.256 ha., es decir, en el 31,93\% del término municipal se llevaba a cabo estas prácticas (tabla 1). Con respecto al total de la superficie cultivada, según el censo de Figueras Pacheco de 1908, la superficie agraria era de 3.100 ha., (el 78\% de todo el término municipal) (tabla 1), siendo sólo de regadío 150 Has. Por lo tanto, la superficie donde se realizaba el aprovechamiento de turbias en relación con el total de la superficie agraria representaba el 40,52\% (tabla 2). Ello evidencia la importancia de esta técnica asociada a la escasez de otros recursos hídricos permanentes y el carácter semiárido de este territorio.

Tabla 1. Superficie del término municipal de San Vicente del Raspeig, 1908.

\begin{tabular}{|l|c|c|c|}
\hline & $\mathrm{m}^{2}$ & ha & $\%$ \\
\hline Superficie total del municipio & 39.340 .000 & 3.934 & 100,00 \\
\hline Superficie total cultivada & 31.000 .000 & 3.100 & 78,80 \\
\hline Superficie regada con aprovechamiento de turbias & 12.562 .162 & 1.256 & 31,93 \\
\hline
\end{tabular}

Fuente: Figueras Pacheco. Elaboración propia.

\subsection{Aprovechamiento de la escorrentía difusa}

Este aprovechamiento consistía en la recogida de la escorrentía de la superficie del terreno, generalmente de zonas con pendiente tras un episodio de lluvias. Se practicaba en zonas donde la naturaleza rocosa del terreno facilitaba que el porcentaje de escorrentía respecto a la lluvia total caída fuera elevada, de esta manera el desarrollo de esta práctica podía ser muy eficaz, incluso con lluvias débiles (Mondéjar, 2009). Se caracteriza por tener una zona de impluvio o captación (donde se recogía el agua de escorrentía en la ladera) y un área de recepción, que eran los bancales de cultivos instalados aguas abajo. Servía para regar directamente pequeñas superficies agrarias o bien almacenar el agua en aljibes, cisternas, pozos, balsas, abrevaderos, etc., de las casas de campo. Para recoger mayor volumen de agua, en el área de impluvio se eliminaba la vegetación típica de las laderas semiáridas (bayones, espinos negros, lentiscos, efedras, salsolas, etc.), consiguiendo reducir la infiltración de los suelos. También se favorecía el crecimiento de espartales puros que eran explotados para la fabricación textil y cuya manufactura suponía un complemento económico extra para la sociedad agrícola de la época (Climent, 1985). El aprovechamiento de la escorrentía difusa se practicaba en San Vicente del Raspeig en el 19,26\% de la superficie total cultivada. Porcentaje que se incrementaba hasta el 47,53\% de la superficie total donde se practicaban las boqueras, que correspondía aproximadamente a una extensión de 597,11 ha. (tabla 2 y figura 1). Dentro de este de aprovechamiento de escorrentías difusas se diferencian varios sistemas como, por ejemplo, el riego de vertiente o de vessant, la derivación de agua para uso doméstico, las boqueras de ladera (según las curvas de nivel o en pendiente) y las cañadas. 
Tabla 2. Superficie regada con aprovechamiento de turbias en relación con la superficie total cultivada, 1908.

\begin{tabular}{|l|c|c|}
\hline & ha & $\%$ \\
\hline ESCORRENTÍA DIFUSA & 597,11 & 19,26 \\
\hline - Vertientes o "vessants" & 98,42 & 3,17 \\
- Derivación de agua para uso doméstico & 132,47 & 4,27 \\
- Boqueras de ladera & 99,82 & 3,22 \\
- Según las curvas de nivel & 35,91 & 1,16 \\
- Según la pendiente & 63,91 & 2,06 \\
- Cañadas & 266,41 & 8,59 \\
\hline ESCORRENTÍA CONCENTRADA & 659,10 & 21,26 \\
\hline - Boqueras de cauce íntegro & 16,81 & 0,54 \\
- Boqueras con dique de derivación & 642,30 & 20,72 \\
\hline SUPERFICIE TOTAL REGADA CON AGUA DE TURBIAS & 1.256 & 40,52 \\
\hline SUPERFICIE TOTAL CULTIVADA & 3.100 & 100 \\
\hline
\end{tabular}

Elaboración propia.

Figura 1. Porcentaje de la superficie regada con aprovechamiento de turbias según tipologías, 1908.

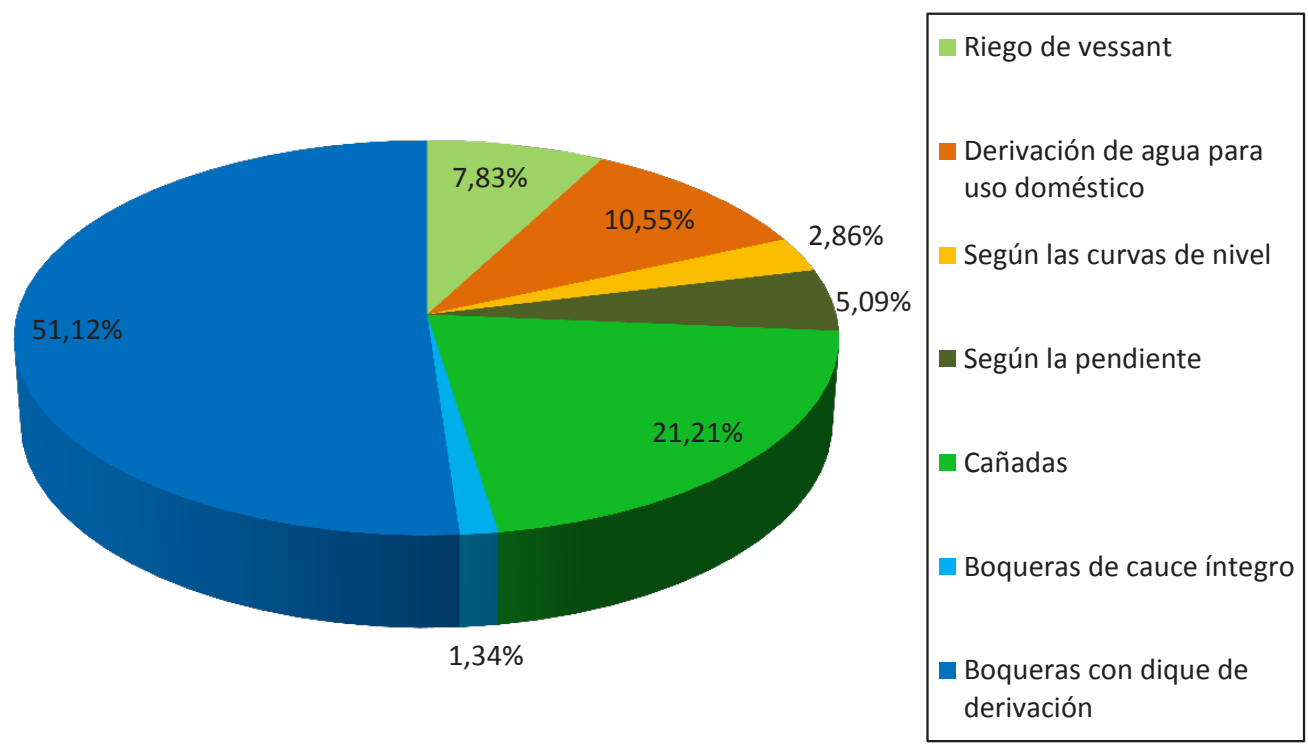

Elaboración propia.

\subsubsection{Vertientes o "vessants"}

Un tipo de boqueras que aprovechaba la escorrentía difusa era el riego de vertiente o de vessant. Éste consistía en la recogida de la escorrentía de las capas más superficiales del suelo, principalmente de las laderas y zonas altas. El aprovechamiento de esta escorrentía no representaba gran dificultad, ya que se hacía "in situ" con la construcción de un vessant o surco excavado en la misma montaña que canalizaba el agua a los bancales ladera abajo y por lo tanto no hacía falta la intervención directa del agricultor. Este sistema se encuentra principalmente en el norte del término municipal, que es el sector más montañoso de la localidad (laderas, vertientes e incluso cauces de amplitud reducida). Estas áreas representaban el 3,17\% 
del total de la superficie cultivada y el 7,83\% del total de la superficie donde se practicaban boqueras, que corresponde aproximadamente a 98,42 ha. (tabla 2 y figura 1). Algunas de estas áreas son las laderas abancaladas de El Xirau (figura 2), El Cardinchalet, El Sabinar, las laderas de la Sierra del Güendo, el Bec de l'Àguila, el Alto de la Coveta Fumà, las vertientes del Plà de la Olivera Alto, la Llometa Reona, etc. (figuras 3 y 4). En general son parcelas abancaladas de pequeña superficie que estaban conectadas en ocasiones con otros sistemas de boquera aguas abajo y que servían para aportar la escorrentía sobrante a éstos últimos. Era el sistema más fácil para el agricultor ya que no necesitaba una tecnología muy compleja y consistía básicamente en el abancalamiento de las laderas para aprovechar el agua de las escorrentías superficiales, además de la posibilidad de almacenar el agua en cisternas, aljibes, abrevaderos, etc.

Figura 2. Superficie donde se aprovechaba la escorrentía difusa con vessants (El Xirau -Partida de Boqueres-).

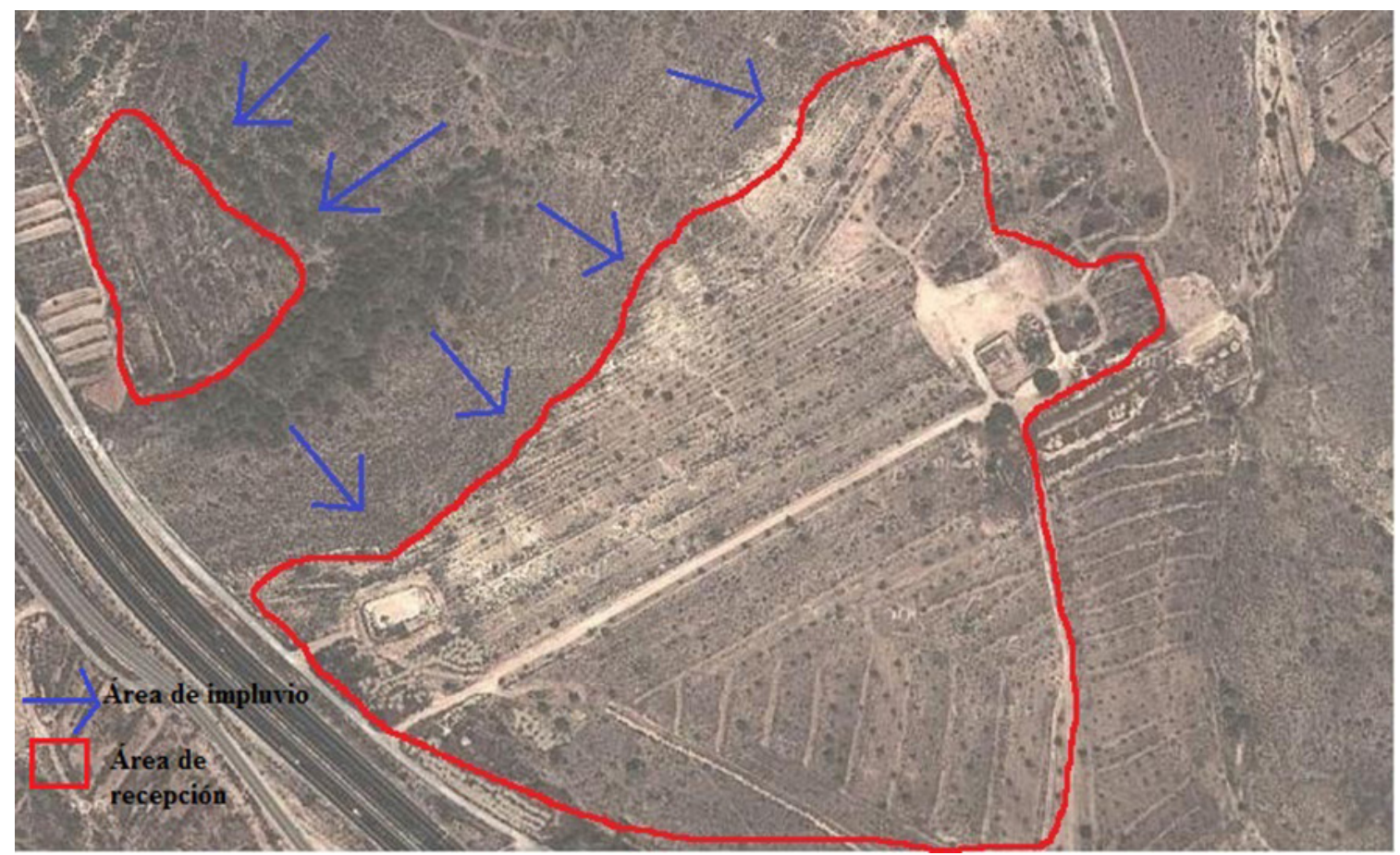

Fuente: http://maps.google.es/maps. Elaboración propia.

\subsubsection{Derivación de agua para uso doméstico: aljibes y abrevaderos}

Otro sistema de aprovechamiento de la escorrentía difusa era la derivación de agua para uso doméstico (aljibes, abrevaderos, etc.). Esta práctica de aprovisionamiento tradicional de agua, que aseguraba unas disponibilidades independientes de la pluviometría, garantizaba el suministro a la población y al ganado (Box, 1995). Los aljibes configuraban un complejo hidráulico que precisaban de diferentes elementos para su correcto funcionamiento como, por ejemplo, las conducciones donde se canalizaba el agua hacia la cisterna (boqueras, agüeras o acequias), pocetas o decantador de nutrientes sólidos, brocales, etc., (Box, 1995). Una característica peculiar de este sistema era que en las zonas donde se recogía el agua, al igual que en los márgenes de las canalizaciones y en la entrada del aljibe, se favorecía el crecimiento de plantas aromáticas como romeros y tomillos para que le diesen un sabor especial a las aguas (Morales, 1969). Las áreas donde se recogía el agua de la lluvia para su posterior almacenamiento se encuentran repartidas por todo el término municipal de forma reducida y dispersa, pues la mayoría de las casas rurales disponían de cisternas o pozos que se llenaban con esta agua. En este caso, la superficie de alimentación está más próxima al aljibe y solían ser bastante más reducida (entre 500 y $1.000 \mathrm{~m}^{2}$ ), además se limpiaba completamente la vegetación y se impermeabilizaba el terreno para que se produjera una escorrentía rápida cuando lloviese (Box, 1995). 
Figura 3. Superficie con aprovechamiento de turbias (zona norte de San Vicente del Raspeig, 1908).

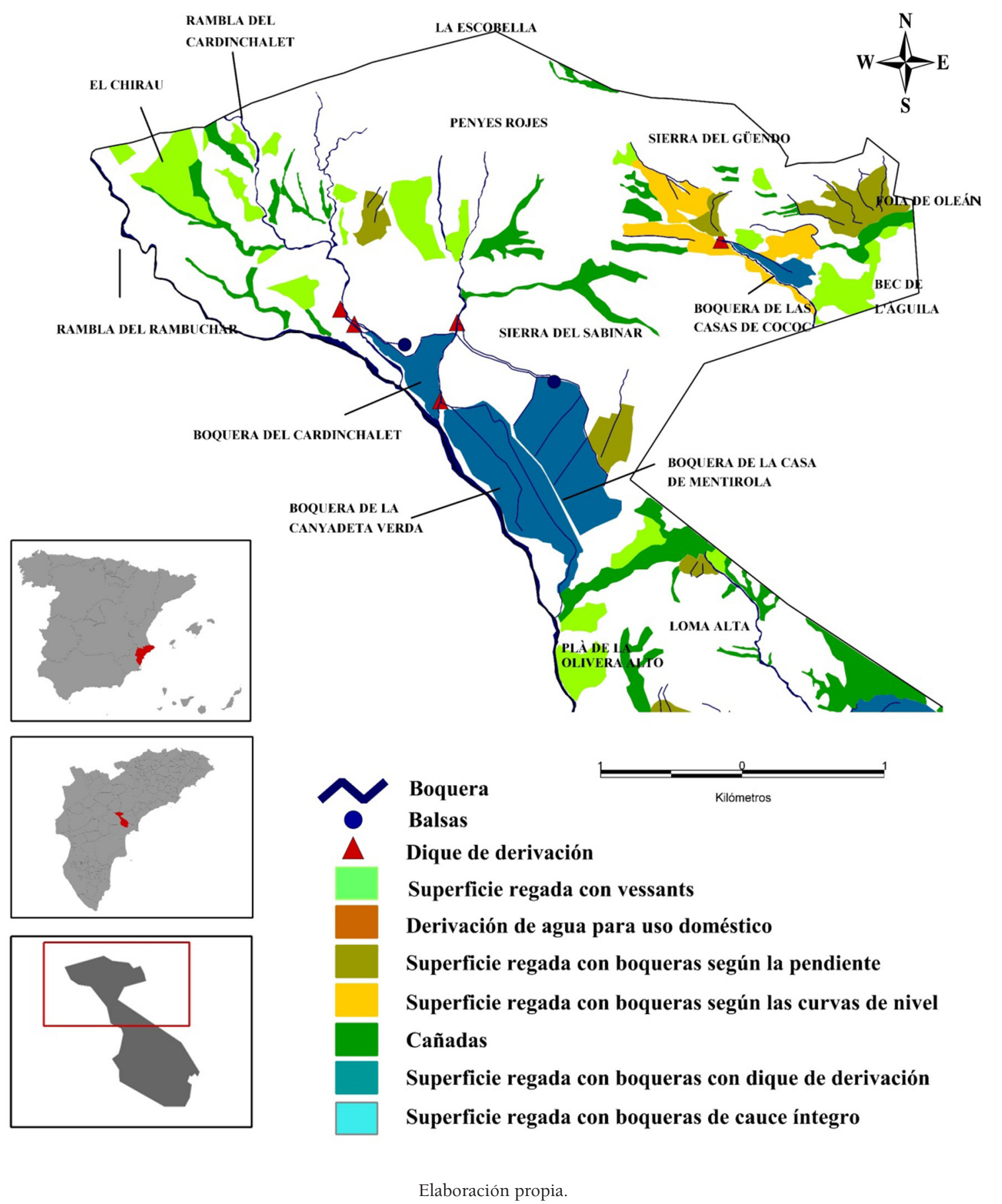

En San Vicente del Raspeig el área más relevante por su extensión y por el caudal de escorrentía recogida exclusivamente para el uso doméstico se encuentra en la zona norte del actual núcleo urbano (figura 4). En esta parte se recogía el agua de la escorrentía difusa que descendía de una vertiente de la zona de El Calvario, además de la recogida de las terrazas y tejados de las viviendas. En El Calvario se alcanza la cota de $153 \mathrm{msnm}$., (es una zona con una cierta pendiente ya que en el centro de la localidad, 800 metros al sur, la altura sobre el nivel del mar ronda los $110 \mathrm{msnm}$.). Desde El Calvario descendía el vessant por la actual calle Lillo Juan y alimentaba las cisternas, pozos y abrevaderos de las viviendas y corrales del núcleo urbano como, por ejemplo, el aljibe de la Casa del Cura (al lado de la iglesia). Este tipo de aprovechamiento 
de turbias para uso doméstico ya se practicaba como mínimo en el núcleo urbano desde el siglo XVIII, pues la cisterna de la Casa del Cura data de 1735. También se encuentran escrituras de la finca "Los Molinos" donde se cita que las vessants o boqueres llegaban hasta la actual calle Sol (centro del núcleo urbano) (Canals, 2012). A pesar de que esta agua era para uso doméstico, la superficie donde se recogía y derivaba el agua representaba el 4,27\% del total de la superficie cultivada, el 10,55\% del total de la superficie donde se practicaban boqueras que correspondía aproximadamente 132,47 ha. (tabla 2 y figura 1 ).

Figura 4. Superficie con aprovechamiento de turbias (zona centro y sur de San Vicente del Raspeig, 1908).

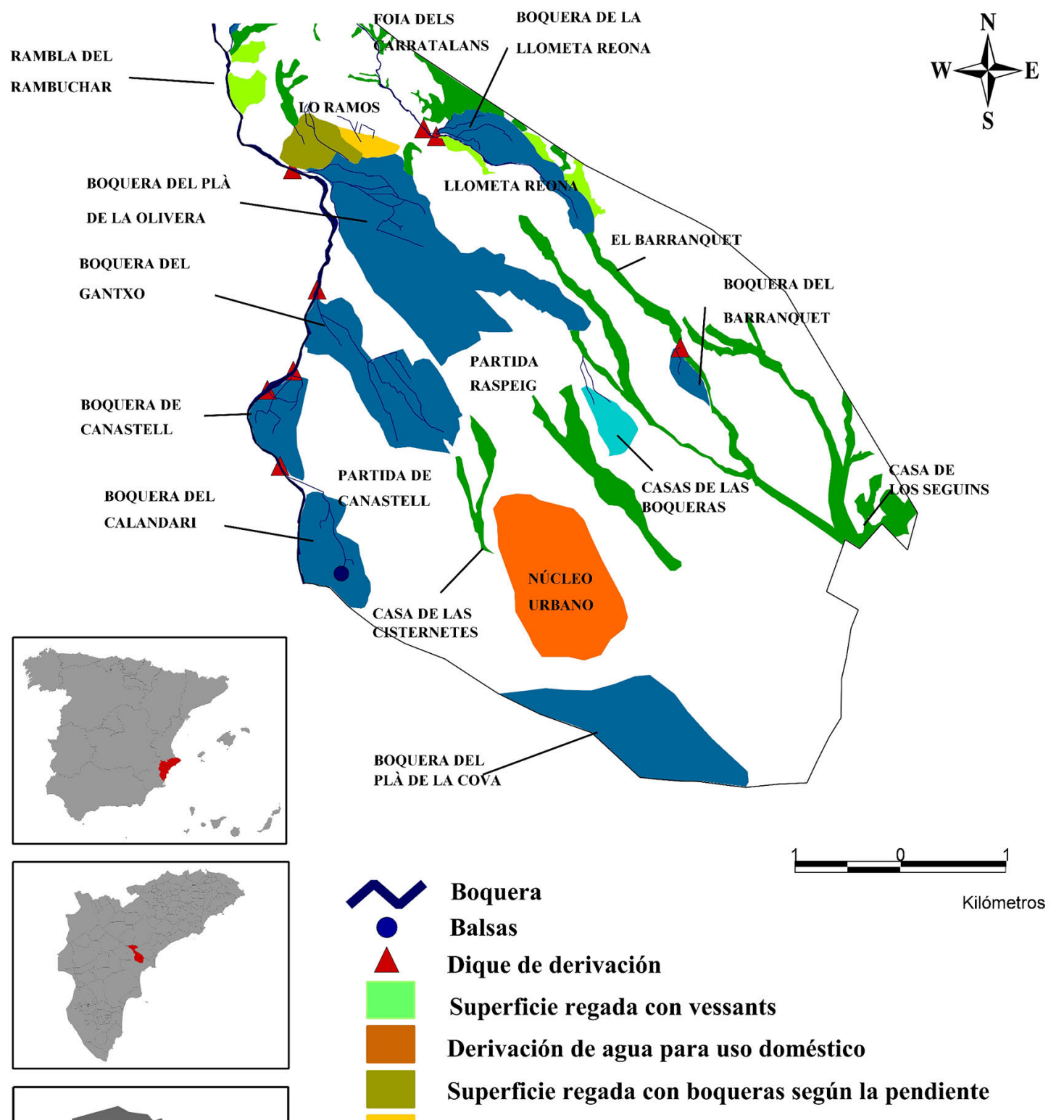

Superficie regada con boqueras según las curvas de nivel

\section{Cañadas}

Superficie regada con boqueras con dique de derivación

Superficie regada con boqueras de cauce íntegro 


\subsubsection{Boqueras de ladera}

Una tercera modalidad de aprovechamiento de la escorrentía difusa son las boqueras de ladera. Las áreas donde se llevaba a cabo este sistema representaba el 3,22\% del total de la superficie cultivada y el $7,95 \%$ de la superficie donde se practicaban boqueras que suponía una extensión aproximada de 99,82 ha. (tabla 2 y figura 1). Esta práctica consistía en la construcción de unas acequias llamadas "boqueras" que transportaban la escorrentía hacia los campos a regar, ya que éstos, en ocasiones, no se encontraban inmediatamente anexos a la zona donde se recogía el agua (área de impluvio) y su superficie solía ser el doble que la de las parcelas de los cultivos. Una característica peculiar era que en los márgenes de las canalizaciones se favorecía una vegetación de tipo arbustiva con la finalidad de que las raíces sujetaran la tierra para frenar la erosión ante episodios de lluvias intensas. La superficie de estas áreas era mayor que las regadas por vessant, ya que podían canalizar más agua y de esta manera regar más superficie y aumentar la productividad de los cultivos.

En esta tipología es posible diferenciar varios subsistemas según la localización y trazado de la canalización. Por una parte, se encuentran las boqueras según las curvas de nivel, es decir, aquéllas que se construyen adaptándose a las curvas de nivel, dotándolas con una pequeña pendiente. Obviamente estas prácticas se realizaban en las zonas de montaña donde hay más pendiente como, por ejemplo, en la Sierra del Sabinar, la Sierra del Güendo, la Foia de Oleán y la Serreta Lo Ramos (figuras 3 y 4). Las boqueras de ladera según las curvas de nivel representaban sólo el 1,16\% del total de la superficie cultivada, el 2,86\% de la superficie donde se practicaba el aprovechamiento de turbias y unas 35,91 ha. (tabla 2 y figura 1). Ello en gran medida es debido a la escasa entidad de los espacios montañosos en el término municipal de San Vicente del Raspeig.

Figura 5. Superficie donde se practicaban las boqueras de ladera según la pendiente (Foia de Oleán -Partida de Boqueres-).

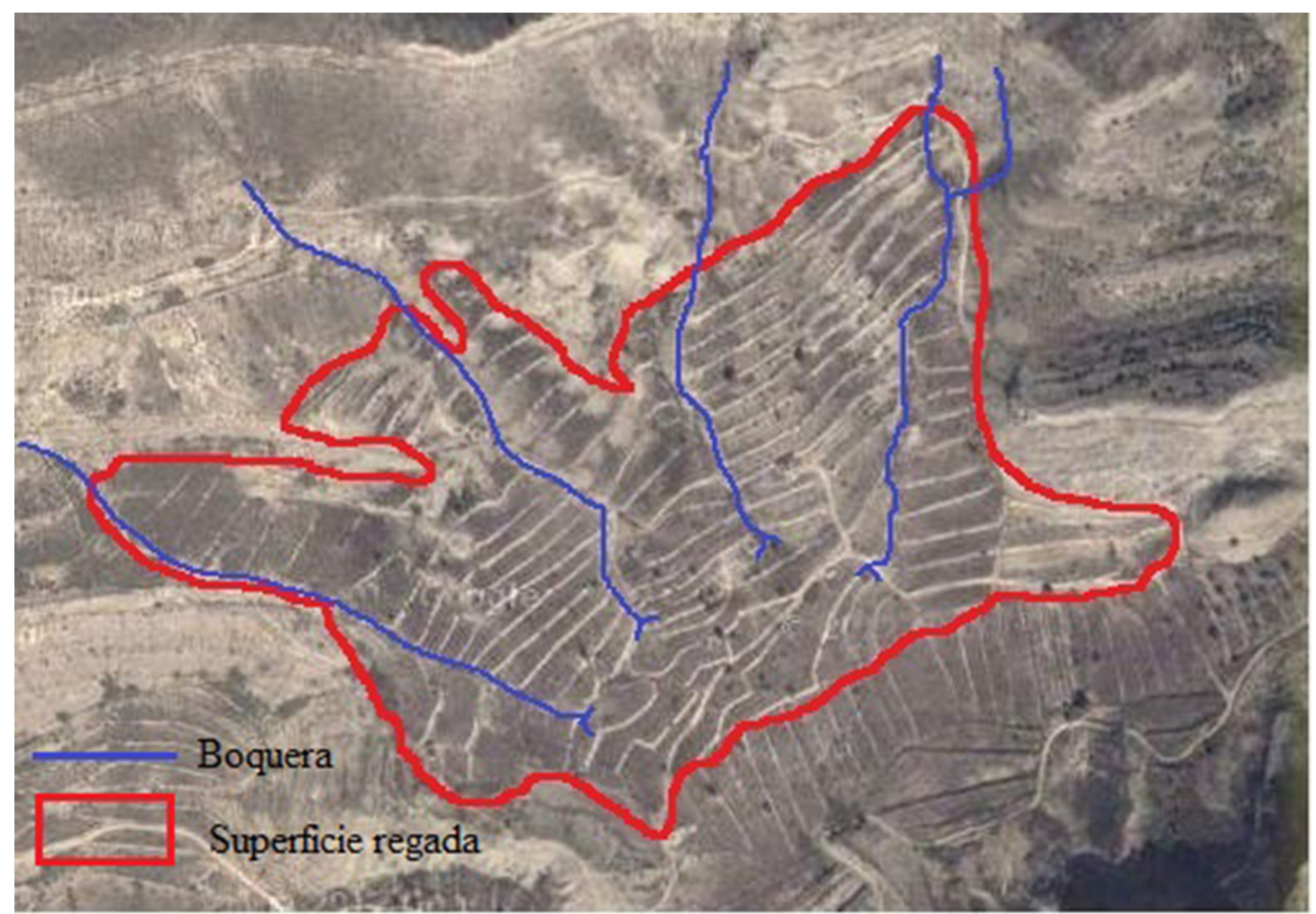

Fuente: http://maps.google.es/maps. Elaboración propia.

Otra modalidad son las boqueras en pendiente o como las denomina Morales (1969), en relieve en cuesta. Este sistema consistía en la construcción de canalizaciones oblicuas a la pendiente del terreno. Un rasgo particular es que el elevado poder erosivo en la ladera acentuado por la pendiente, se convierte en 
un hecho positivo ya que a partir de esos materiales erosionados se creaba suelo nuevo y se enriquecía con nutrientes los campos de cultivo. La elección de una tipología u otra dependía de la naturaleza del terreno o la proximidad de las parcelas a regar, ya que si éstas se encontraban a escasos metros aguas abajo de la ladera, el sistema de boqueras en pendiente era el más práctico. Éste, representaba el 2,06\% del total de la superficie cultivada y el 5,09\% del total de la superficie donde se practicaba el aprovechamiento de turbias, que correspondía aproximadamente unas 63,91 ha. (tabla 2 y figura 1). Las áreas donde se llevaban a cabo estas prácticas se encuentran en el Altet del Pichot (El Xirau), Les Penyes Rojes, la Sierra del Güendo, la Foia de Oleán (figura 5), la Sierra del Sabinar, el Plà de la Olivera Alto y la Serreta Lo Ramos. La mayoría de estas boqueras aún siguen en funcionamiento (aunque los campos están abandonados), más bien parecen pequeños torrentes erosionados que descienden de las partes más altas. En la zona de la urbanización del Pozo San Antonio (Plà de la Olivera Alto) y del Sabinar, estas canalizaciones han sido sustituidas por calles y caminos, incluso algunas de ellas sirven como límites entre chalets que han ido ocupando parte de la antigua zona regada.

\subsubsection{Cañadas}

Este tipo de aprovechamiento de la escorrentía difusa se practica "in situ", es decir, en el propio lecho del cauce de la rambla formando terrazas en graderío o como se conoce en estas tierras, cañadas o foies. Como indica Mondéjar (2009), varias son las condiciones que deben cumplir los cauces para ser aprovechados de forma directa: poseer la suficiente anchura, que se encuentre topográficamente ordenado de manera que sea posible el laboreo, que esté situado en un nivel de cuenca vertiente en el cual la velocidad del flujo no sea excesivamente alta y que la fuerza erosiva pueda ser atenuada facilitando el riego. Las cañadas cultivadas en San Vicente del Raspeig representaban el 8,59\% del total de la superficie cultivada, el $21,21 \%$ del total de la superficie donde se practicaban las boqueras que corresponde a una superficie aproximada de 266,41 ha. (tabla 2 y figura 1 ). Se encuentran repartidas por todo el término municipal. En la parte norte hay un gran número de ellas, aunque son más estrechas y con más pendiente ya que se han instalado sobre ramblas o torrentes que descienden de las laderas. En cambio, en la parte sur y centro, las cañadas tienen una anchura y longitud mayor debido a que el terreno es más llano y no hay presencia de sectores montañosos (figura 4). En este sector se aprovechaban los barrancos que descienden de la parte central del término municipal (partida de Canastell, la Llometa Reona, partida El Raspeig, la Bayona Alta y Baja). Un elemento constructivo asociado a las cañadas son los parats. Son unos muros, presas o ribazos que se instalan en el mismo cauce con el objetivo de frenar la erosión y depositar los materiales que arrastra la escorrentía aguas arriba. Este hecho favorecía la percolación de las aguas de lluvia que recibían estos bancales, creando una corriente subálvea en la base del parat (Morales y Box, 1986). Estos flujos se aprovechaban una vez se canalizaban para ser depositados en aljibes o pozos. Un ejemplo de estos parats es el de las Casas de Las Cisternetes (partida de Canastell) que facilitaba la percolación de la escorrentía a las cisternas de estas viviendas (de ahí su nombre). Otro ejemplo es el parat de la Casa de Los Seguins que cuenta con más de 2 metros de altura. Otro elemento constructivo asociado a las cañadas eran los sangradores. Éstos servían para evacuar el agua hacia los bancales inferiores una vez se había inundado el que se encuentra aguas arriba. La presencia de estas terrazas escalonadas y comunicadas entre sí por una abertura central (sangrador), que no profundiza hasta la base del caballón o mota de cerramiento, represaba el agua y facilitaba la infiltración, que operando sobre grandes superficies, generaba un importante déficit de escorrentía (Gil, 1983).

Prototipo de una rambla utilizada como cañada es El Barranquet (figura 6). Este barranco tradicionalmente ha servido como zona de cultivo y se caracteriza por que en él se encuentran una gran variedad de partidores, pequeños diques, sangradores, canalizaciones, etc., que incluso transportaban el agua a parcelas colindantes. En la zona donde se sitúan las Casas del Barranquet (figura 4) había un dique de derivación que desviaba la escorrentía con la instalación de tablachos que se disponían transversalmente al cauce. También destaca esta rambla por la complejidad y combinación de diversas técnicas de boqueras: en la parte alta de su cuenca, la escorrentía es desviada por diques de derivación, además de recibir agua de boqueras de ladera y vessants como ocurre en la mayoría de estos sistemas. 
También se encuentran numerosos topónimos en San Vicente del Raspeig relacionados con las cañadas o foias como, por ejemplo, la Foia de Oleán, la Canyadeta Verda, Foia dels Carratalans, Foia Molina, Casas de la Cañadeta (partida de Boqueres), Casas de la Cañaeta (partida Raspeig), etc.

Figura 6. Rambla utilizada como cañada (El Barranquet-Partida El Raspeig-).

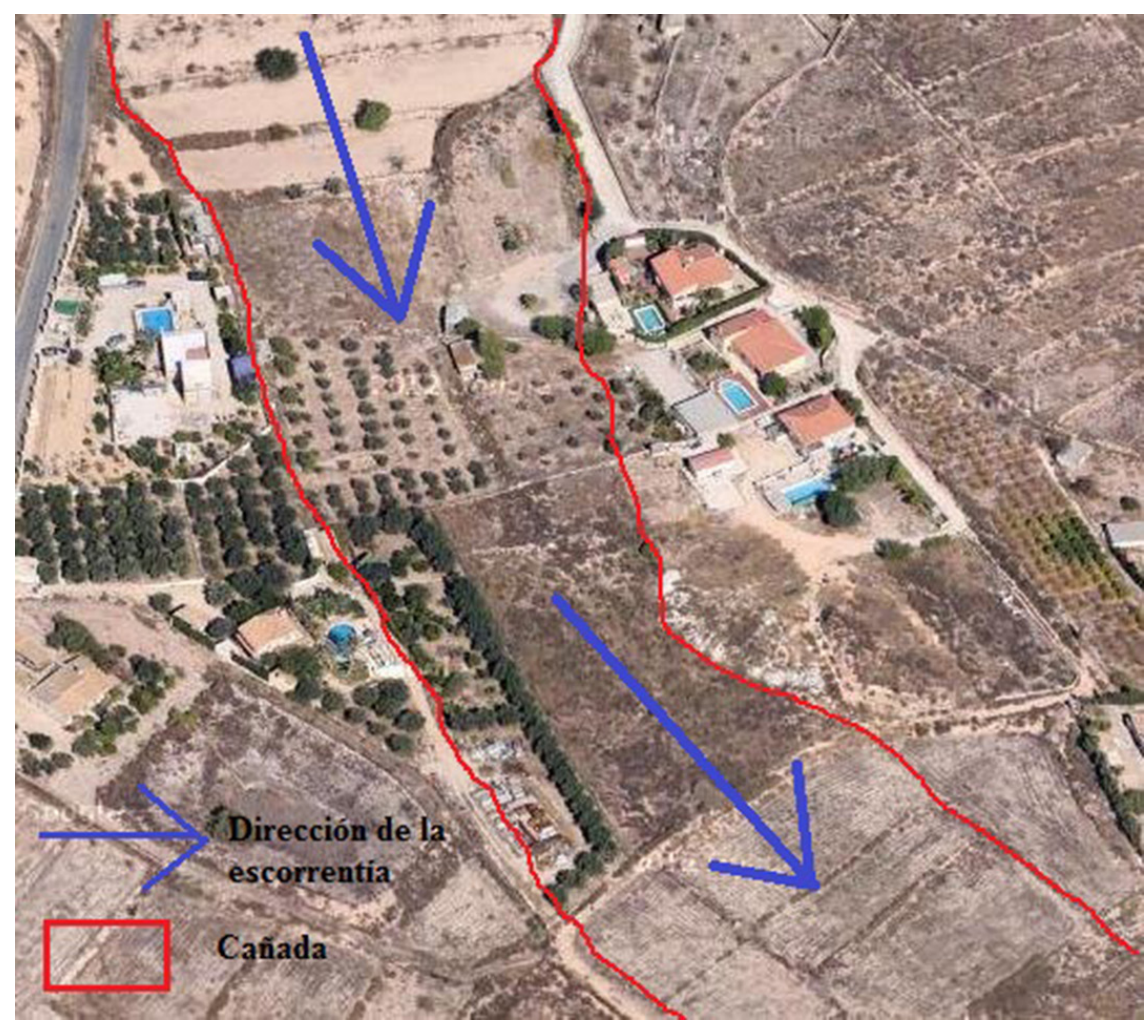

Fuente: http://maps.google.es/maps. Elaboración propia.

\subsection{Aprovechamiento de la escorrentía concentrada}

Esta técnica consistía en la desviación de la escorrentía circulante de las ramblas y barrancos mediante unos canales, que era donde se acumulaba más volumen de agua, y por lo tanto, mayor velocidad del caudal y superficie agrícola a regar. Con este sistema se hacía más complicado recoger el agua, por lo que era necesario emplear técnicas y elementos hidráulicos más complejos para poder gestionar y regular la escorrentía. El aprovechamiento de la escorrentía concentrada se practicaba en el 21,26\% del total de la superficie cultivada y en el $52,47 \%$ de la superficie donde se practicaban boqueras, que correspondía aproximadamente a 659 ha. (tabla 2 y figura 1). Es decir, la mitad de la superficie donde se utilizaban técnicas de inundación dirigida se hacía con este sistema de derivación, ya que permitía recoger más caudal de las ramblas y por lo tanto, la superficie regada era mayor, al igual que también se podía almacenar más volumen de agua en balsas y aljibes. En esta tipología se diferencian dos subtipos. Uno de ellos es el que utiliza la boquera de cauce íntegro, mientras que el segundo es el que deriva la escorrentía de las ramblas y barrancos gracias a la construcción de un dique en el mismo lecho del cauce.

\subsubsection{Boqueras de cauce integro}

Esta técnica se practicaba cuando no se podía cultivar en el mismo lecho de la rambla. De esta manera, se construía una boquera y se desviaba la escorrentía hacia los campos de cultivo, que por norma general estaban próximos al cauce. La canalización se instalaba en el mismo cauce y en una zona de ladera, por lo tanto, además de ser regados, se abonaban los campos con limos y arcillas creando suelo nuevo. Este 
tipo de aprovechamiento sólo se encuentra en un área en San Vicente del Raspeig, concretamente donde se ubican las "Casas de Boqueras" (figura 4). Teniendo en cuenta que estas viviendas son anteriores al siglo XVIII, se puede afirmar que ya en esta fecha se utilizaba este sistema en esta zona. En concreto, la boquera (de unos 250 metros de longitud) canalizaba a través de un partidor la escorrentía de una pequeña rambla que ha sido utilizada como cañada. Sólo representaba el 0,54\% del total de la superficie cultivada, el 1,34\% de la superficie donde se practicaban boqueras que corresponde aproximadamente a 16,81 ha. (tabla 2 y figura 1 ).

\subsubsection{Boqueras con dique de derivación}

La práctica de este aprovechamiento precisaba la construcción de una presa o dique transversal a la dirección de la escorrentía. La presa tenía como finalidad desviar el agua a través de un canal que posteriormente era canalizada hacia los campos de cultivo. El dique de derivación era generalmente de poca altura (1 metro aproximadamente) y sólo aprovechaba el caudal necesario, por lo tanto, en ocasiones, no ocupaba todo el cauce. Este hecho se veía condicionado asimismo porque aguas abajo también tenían derecho, tal y como era recogido por la jurisprudencia, para aprovechar el caudal otros agricultores (Morales et al., 1989). Los diques más utilizados solían estar construidos de tierra o piedra (que eran reconstruidos tras las lluvias), ya que eran los más económicos, además de que no necesitaban autorización para su levantamiento (art. 177 de la Ley de Aguas de 1879). Si el dique era permanente solía estar construido de mampostería para poder resistir la fuerza del agua y podrían ser de varios tipos: de tipo malecón, transversal con boquera lateral (figura 7), con doble boquera a izquierda y derecha del dique y con dique transversal para la formación de un meandro abandonado.

Figura 7. Dique de derivación transversal con boquera lateral (imagen izquierda) y de tipo malecón (imagen derecha).

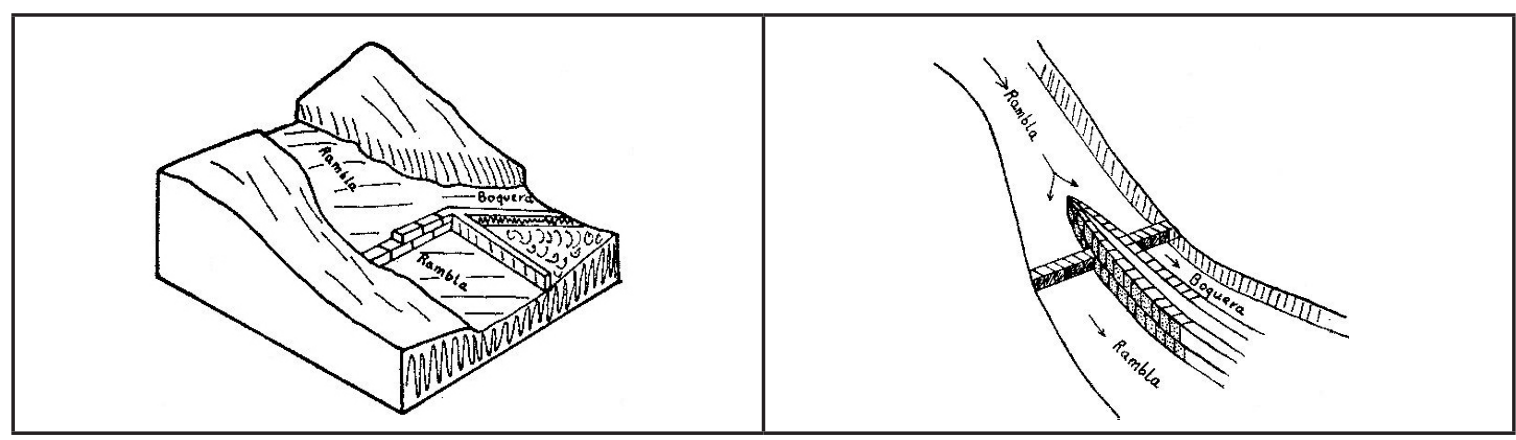

Fuente: Morales, 1969.

De manera general, los grandes sistemas de boqueras con dique de derivación disponían de elementos y técnicas constructivas para poder manejar y controlar la fuerza y la velocidad del agua de avenida y de este modo tratar de aminorar los daños que en el sistema pudieran generar unos caudales o una velocidad excesivos. Una de ellas era lograr una pendiente ascendente en el primer tramo de la boquera para contrarrestar la fuerza de empuje de la escorrentía. También se construía una balsa o decantador al inicio de la boquera para que las aguas se embalsasen y de esta manera iniciar su recorrido con velocidad 0. Otro elemento constructivo era la instalación de una compuerta de regulación del caudal para dejar pasar exclusivamente el agua necesaria y la construcción de un aliviadero con el fin de disminuir el caudal y su velocidad a la entrada de la boquera. Con esta práctica se retornaba parte de la escorrentía al barranco ya que un volumen excesivo podía poner en riesgo todo el sistema debido a la fuerza de la avenida. Otra técnica consistía en descender la cota del dique de derivación, frecuentemente utilizada en azudes, ya que se construían sobre cauces que podían llevar bastante caudal como, por ejemplo, los azudes del Río Montnegre. Este sistema se llevaba a cabo cuando el año había sido lluvioso y los campos estaban suficientemente regados (en raras ocasiones en estas tierras). Por lo tanto, los portones o tablachos que había en la parte superior del dique de derivación se quitaban, logrando disminuir la cota y el calado impidiendo el paso del agua a la boquera. 
En función de la superficie a regar o del caudal que podía llevar la rambla, la red del sistema de riego podría ser más o menos compleja (Alberola, 1994). Por ejemplo, en un sistema complejo de canalizaciones se encuentra la boquera o acequia principal, denominada también como acequia mayor o eje. De esta acequia principal salen las acequias de primer orden o brazales y de éstas, las hijuelas, que a su vez se dividen en subramales (Morales y Bru, 1984).

La práctica de boqueras con dique de derivación es el que potencialmente más extensión podía llegar a regar, dada la complejidad de la red de distribución. En San Vicente del Raspeig representaban el $20,72 \%$ del total de la superficie cultivada y el $51,12 \%$ del total de la superficie donde se practicaba el aprovechamiento de turbias que aproximadamente correspondían a unas 642,30 ha., teniendo en cuenta que el total de la superficie cultivada en el término municipal a principios del siglo XX era de 3.100 ha. (tabla 2 y figura 1). En la localidad se encuentran dos áreas diferenciadas donde se practicaba este tipo de aprovechamiento (escorrentía concentrada). Por un lado destacan los barrancos de la cuenca de la Rambla del Rambuchar (parte norte y oeste) y, por otro, las ramblas de la cuenca del Barranco del Juncaret (parte norte y este).

En la parte más septentrional de la cuenca de la Rambla del Rambuchar destaca la "Boquera del Cardinchalet" que se sitúa en un afluente de esta rambla (figura 3). Esta boquera tiene dos diques de derivación. El primero desmantelado por la construcción de una carretera tenía una longitud aproximada de 18 metros, una altura de 1,70 metros y 1 metro de ancho (Moratalla, 2000). Desde esta presa el agua se podía canalizar tanto por el margen derecho como por el izquierdo. En el margen derecho se desviaba por una acequia (cegada en la actualidad), que también transportaba agua de una fuente ubicada aguas arriba (la Font del Llop) y que a unos 120 metros más abajo, la acequia salva el barranco mediante un acueducto (figura 8). Esta canalización, según consta en las inscripciones hechas en los ladrillos que se utilizaron en su construcción, dataría de finales del siglo XIX o principios del XX (Moratalla, 2000) y servía para transportar el agua hacia la balsa de la Casa de la Canyadeta Verda y de la Casa de Mentirola. El segundo dique de derivación se sitúa 40 metros aguas abajo del primero. De éste aún se conservan algunos restos de su estructura, tenía unos 1,55 metros de altura, 1,25 metros de ancho y unos 20 metros de longitud (Moratalla, 2000). La construcción de ésta presa es anterior a la primera y la superficie regada aproximada a partir de los dos diques de derivación era de 12,66 ha. (tabla 4).

Figura 8. Acueducto de la "Boquera del Cardinchalet" (Partida de Boqueres).

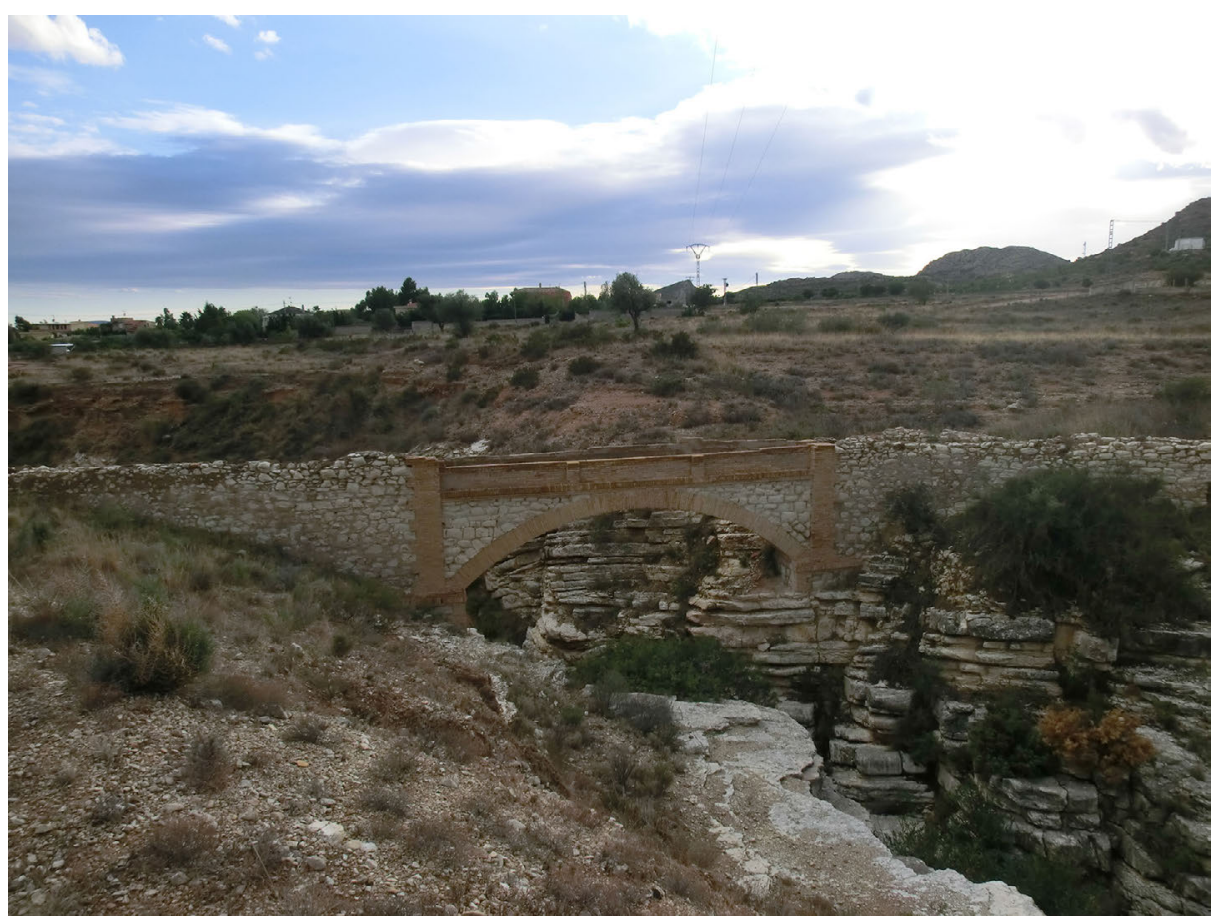


Tabla 4. Superficie regada con aprovechamiento de turbias a partir de diques de derivación, 1908.

\begin{tabular}{|c|l|c|c|}
\hline & & ha & \% \\
\hline \multirow{7}{*}{ Cuenca del Rambuchar } & Boquera del Cardinchalet & 12,66 & 1,97 \\
& Boquera de la Casa de Mentirola & 41,19 & 6,41 \\
& Boquera de la Canyadeta Verda & 46,33 & 7,21 \\
& Boquera del Plà de la Olivera & 197,75 & 30,79 \\
& Boquera del Gantxo & 95,62 & 14,89 \\
& Boquera de Canastell & 31,95 & 4,97 \\
& Boquera del Calandari & 46,77 & 7,28 \\
& Boquera del Plà de la Cova & 111,28 & 17,33 \\
\hline \multirow{5}{*}{ Cuenca del Juncaret } & Boquera de las Casas de Cococ & 5,60 & 0,87 \\
& Boquera de la Llometa Reona & 44,11 & 6,87 \\
& Boquera del Barranquet & 8,99 & 1,40 \\
\hline & Total & 642,30 & 100 \\
\hline
\end{tabular}

Elaboración propia.

La "Boquera de la Casa de Mentirola" (figura 3) desviaba el agua del Barranco del Sabinar (en la actualidad no quedan restos del dique de derivación). La superficie regada era aproximadamente de unas 41,19 ha. (tabla 4), aunque es cierto, que parte del caudal procedía de la "Boquera del Cardinchalet", además de la escorrentía difusa recogida por las boqueras de ladera que descienden de la Sierra del Sabinar.

Aguas abajo del Barranco del Sabinar se ubica otro dique de derivación, en este caso vinculado a la "Boquera de la Canyadeta Verda" (figura 3). Está muy deteriorado y destaca por tener en el primer tramo de la boquera una pendiente ascendente para frenar la velocidad del caudal canalizado, además de un posible aliviadero. La superficie regada aproximada era de 46,33 ha. (tabla 4). Esta zona también podría regarse con el caudal sobrante de la escorrentía recogida en los terrenos de la "Boquera de la Casa de Mentirola" que se sitúa ladera arriba.

En la Rambla del Rambuchar es donde se encuentra el mayor número de boqueras vinculadas a diques de derivación. Destacan tanto los diques que reparten el agua hacia la partida del Moralet y la Cañada del Fenollar (Alicante) como a la zona de San Vicente del Raspeig, siendo este último el objeto de estudio. La presa más al norte de esta rambla que derivaba las aguas hacia el término municipal de San Vicente del Raspeig es la "Boquera del Plà de la Olivera" (figura 4). De la presa (ya desaparecida) partía la acequia Mayor y posiblemente con aliviaderos en la entrada. Aguas abajo se bifurcaba a partir de un partidor en 3 brazales con 3 orientaciones distintas. Representaba la mayor superficie regada por aprovechamientos de turbias en el municipio, ya que si el caudal recogido era importante, podría regar aproximadamente hasta 197,75 ha., es decir el 30,79\% del total de las boqueras con dique de derivación (tabla 4) y llegando el caudal canalizado incluso hasta las parcelas del norte de la partida El Raspeig. Además, habría que sumar la escorrentía que se recogía por las boqueras de ladera y vertientes de la Loma Alta, la Serreta Lo Ramos y la Llometa Reona que desembocan en esta zona.

En la partida de Canastell también se encuentran tres áreas en las que se aprovechaba la escorrentía concentrada a través de diques de derivación sobre la Rambla del Rambuchar. De estos diques o presas no queda ningún resto y las boqueras vinculadas a ellos destacan en los tres casos por tener una pendiente ascendente en el primer tramo. Una de ellas era la "Boquera del Gantxo" (figura 4), donde la superficie regada aproximada era de 95,62 ha. (tabla 4). Es la tercera boquera con dique de derivación que podía regar más extensión de cultivos de secano en el municipio (el 14,89\% del total de las boqueras con dique de derivación). Ha sido junto con la "Boquera del Plà de la Olivera" la causante de algunos episodios de inundación a principios del siglo XX, ya que por ejemplo la Rambla del Rambuchar "se salió" por estas canalizaciones el 29-09-1919 llegando a inundar viviendas en el núcleo urbano (Canals, 2010). 
A unos 800 metros aguas abajo, sobre el antiguo Camino de Agost a Busot se encuentra la "Boquera de Canastell". De la presa original no quedan restos, aunque siguiendo la rambla 250 metros más abajo hay una presa más reciente (primera mitad del siglo XX) que derivaría el agua tanto hacia la zona de Alicante (El Moralet) como a la de San Vicente del Raspeig. Destaca también porque parte del caudal sobrante que se recogía era devuelto a la rambla. La superficie regada era de 31,95 ha. (tabla 4) y parte del entramado del sistema de canalizaciones aún se puede observar, incluso han sido utilizados como caminos (figura 9).

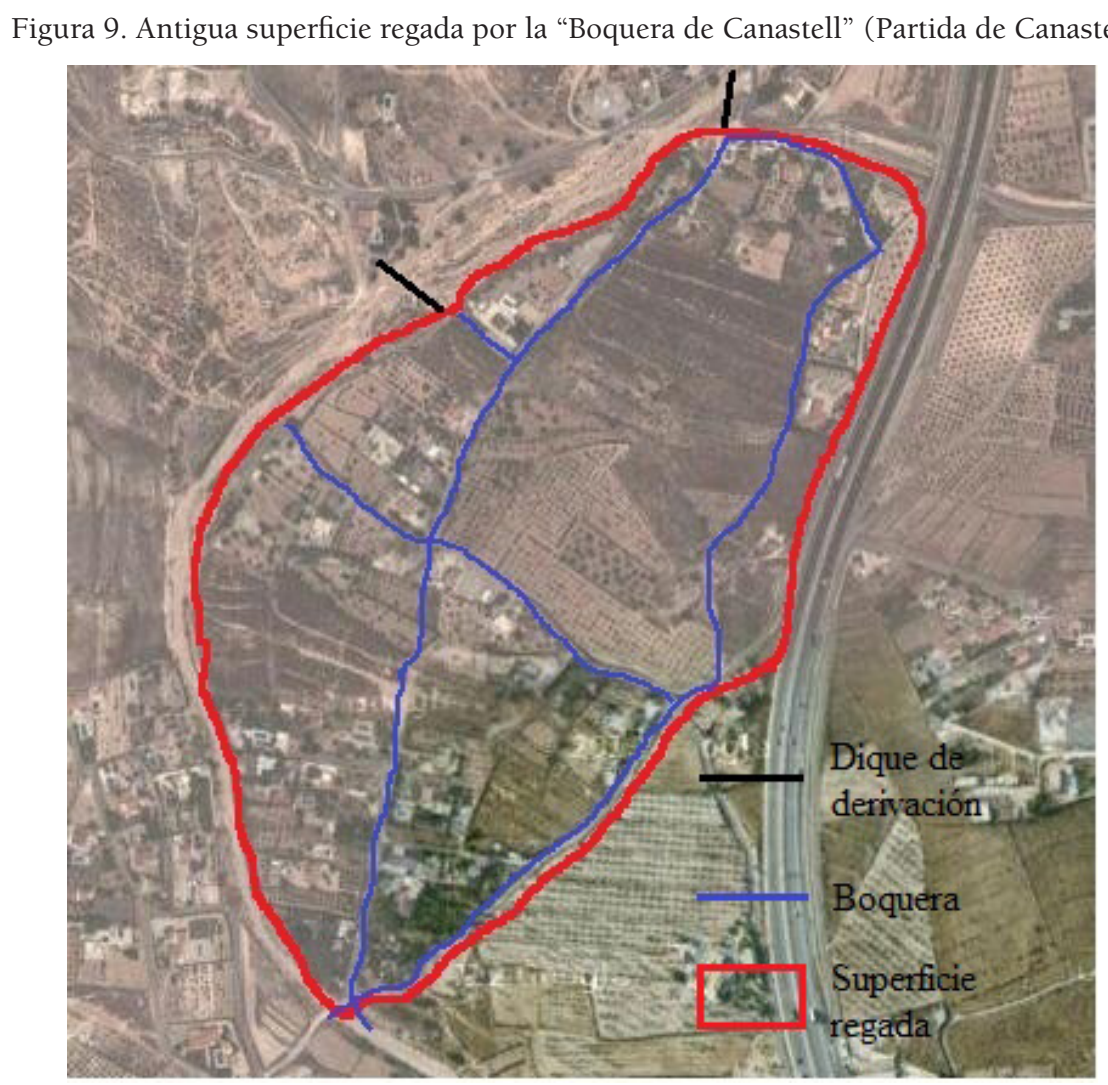

Fuente: http://maps.google.es/maps. Elaboración propia.

A unos 900 metros aguas abajo de la anterior, a escasos metros del puente de la carretera de Agost se encuentra la "Boquera del Calandari" (figura 4). La superficie regada aproximada era de 46,77 ha. (tabla 4) y compartía terrenos con la partida de Inmediaciones, aunque con la construcción del ferrocarril en 1858 la superficie regada quedó dividida, permitiendo sólo la llegada de agua a los cultivos situados al norte de esta vía férrea.

En los terrenos donde en la actualidad se ubica la Universidad de Alicante, al sur del núcleo urbano, zona conocida como el Plà de la Cova, también es un área donde se aprovechaba la escorrentía concentrada. En este caso desde la Rambla del Rambuchar, que se sitúa en el término municipal de Alicante (Cañada del Fenollar), el caudal era derivado a partir de la "Boquera del Plà de la Cova". Esta zona se caracteriza por ser un llano con poca pendiente (alrededor de 85-100 msnm.) que se conoce también como El Fondet (zona endorreica), además de corresponder a un área de ruptura de drenaje de la Rambla del Rambuchar y en la que se retiene los aportes fluviales que con totales pluviométricos reducidos no son evacuados hacia el Barranco de las Ovejas (Morales et al., 1983). Esta área beneficiada con este sistema de boqueras ocupaba 111,28 ha., de cultivos de secano (la segunda en extensión) (tabla 4) y fue desorganizada a raíz de la construcción del Campo de Aviación en 1910. En la actualidad ha sido ocupada por la Universidad, que junto a otros usos urbanos o vías de comunicación, tradicionalmente han actuado de barrera frente a la escorrentía que desciende hacia Alicante, imposibilitando su evacuación y causando inundaciones como, por ejemplo, las acaecidas el 20 de Octubre de 1982 o el 30 de Septiembre de 1997. 
El otro gran conjunto de tierras beneficiadas con sistemas de boqueras con diques de derivación se localizan en la cuenca del Juncaret. Una de ellas es la "Boquera de las Casas del Cococ" que se sitúa en el Sabinar. En la actualidad aún quedan restos de la presa que desviaba el agua del curso alto del Barranco del Juncaret (figura 10). La boquera tiene una anchura de 4 metros (más ancho incluso que el propio barranco) y posiblemente tuviera un aliviadero. La superficie regada era sólo de 5,6 ha. (tabla 4) y los caudales se completaban con la escorrentía difusa captada por las boqueras de ladera y las vertientes de la Sierra del Güendo, la Sierra del Sabinar y la Foia de Oleán.

Figura 10. Dique de derivación de la "Boquera de las Casas del Cococ" (El Sabinar).

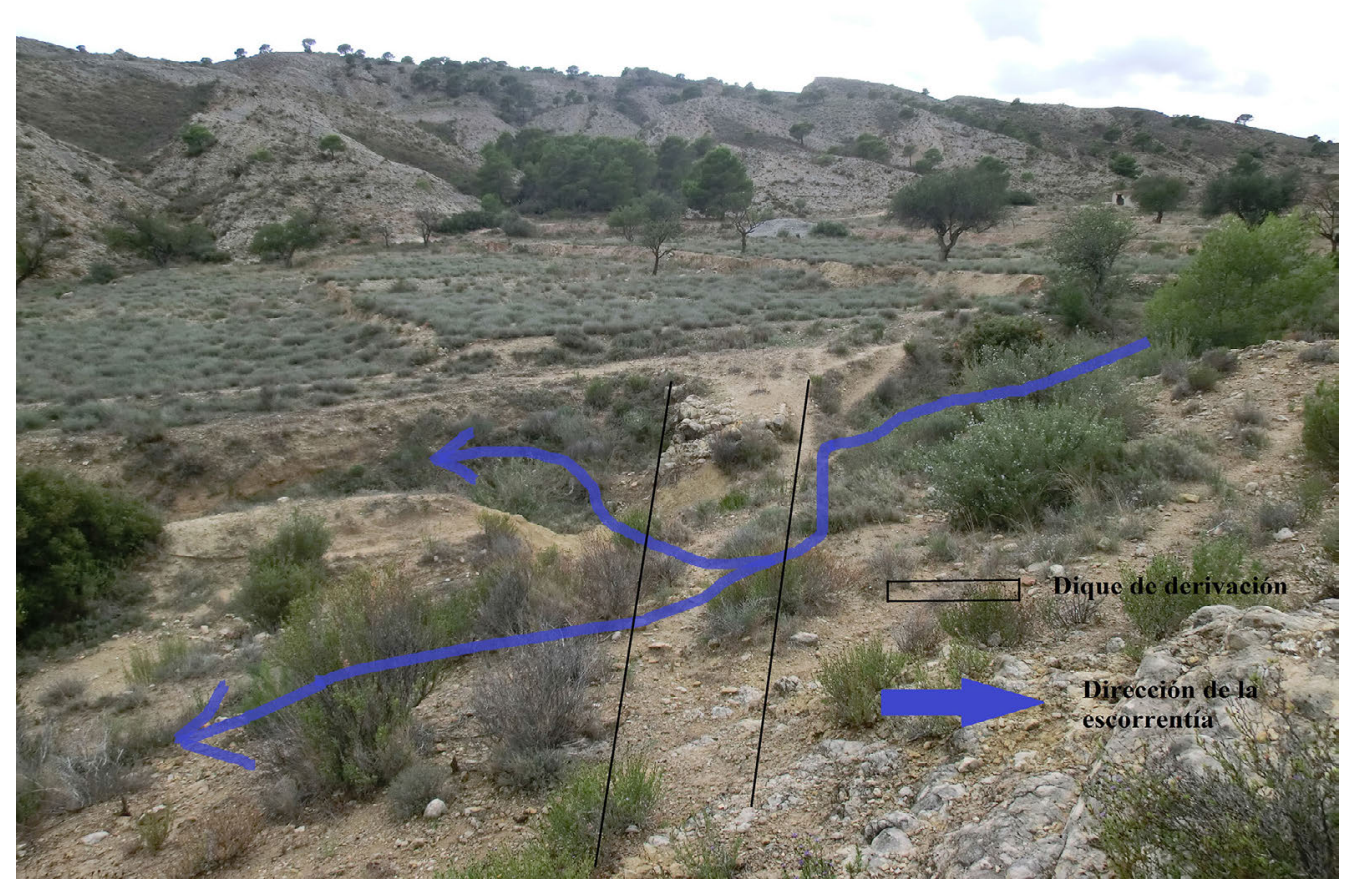

Otro ejemplo de la cuenca del Juncaret es la "Boquera de la Llometa Reona" (figura 11). Canalizaba la escorrentía de una rambla que aguas abajo en la partida El Raspeig es conocida como El Barranquet y que cuando discurre por Villafranqueza se denomina Barranco de Orgegia y al unirse con el Juncaret forman el Barranco de Maldo que desagua en la Albufereta. El sistema de esta boquera está compuesto por dos diques de derivación. El más septentrional es el más antiguo y el que en peores condiciones se encuentra. Pudo tener en sus orígenes unos 12 metros de longitud y 2 metros de ancho. A partir de él se canaliza una boquera que se dirige siguiendo las curvas de nivel hacia la Foia dels Carratalans. La segunda presa se conserva en mejor estado. Pudo tener unos 10 metros de longitud y 1 metro de ancho y se caracteriza por tener un partidor con dos bocas, desde donde se bifurcan dos boqueras, además de tener un posible aliviadero. Todo este sistema se controlaba desde una caseta ubicada en la parte superior del dique (hoy sólo quedan restos) (Moratalla, 2000). La fecha de construcción de esta segunda presa es del último tercio del siglo XIX. Esta fecha se puede confirmar debido al establecimiento general del sistema métrico decimal que se aplicó a partir de 1868, ya que la anchura de las bocas de los portones es de 1 metro (Moratalla, 2000). Las dos acequias se dirigen hacia los campos de cultivo de la Casa de Los Brotons. Una lo hace por la parte norte y la otra desciende paralela a la rambla. Esta boquera se caracteriza por la complejidad del entramado de canalizaciones (acequias mayores, brazales, hijuelas, etc.) e incluso el propio cauce del barranco, a unos 1.100 metros aguas abajo es canalizado como una acequia porque gran parte del caudal era extraído aguas arriba y por lo tanto, había perdido su función natural al igual que prácticamente la totalidad de su caudal. La superficie regada era de unas 44,11 ha. (tabla 4) y como se ha comentado, el cauce de la rambla se convertía en una simple acequia y posteriormente en cañada. 
Figura 11. Segundo dique de derivación de la "Boquera de la Llometa Reona" (Foia dels Carratalans).

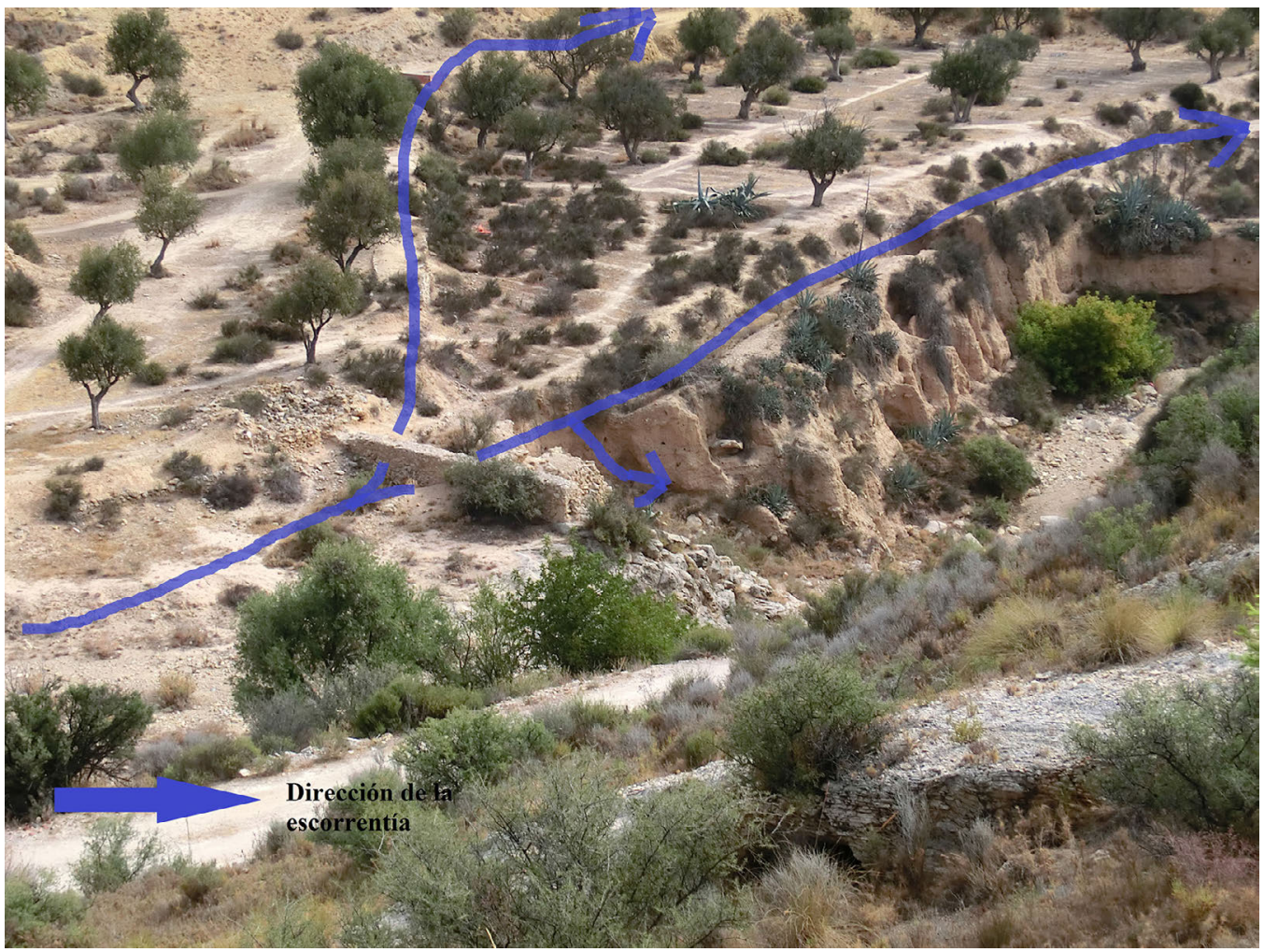

Por último, a unos $3 \mathrm{Km}$., aguas abajo en las Casas del Barranquet se encuentra la "Boquera del Barranquet". El agua era desviada desde la misma rambla, que es utilizada como cañada, a través de un dique de derivación que estaba compuesto por tablachos (aún quedan restos de los partidores) hacia los campos de cultivo que se encuentran contiguos al barranco ocupando una superficie aproximada de 8,99 ha. (tabla 4).

\section{CONSECUENCIAS AMBIENTALES Y PROBLEMÁTICAS DERIVADAS DEL ABANDONO DEL SISTEMA DE APROVECHAMIENTO DE TURBIAS}

El abandono de los sistemas de aprovechamientos de turbias se ha ido produciendo en San Vicente del Raspeig a lo largo del siglo XX, llegándose a practicar residualmente en pequeñas áreas hasta 1960. Este sistema basado en la captación esporádica de los recursos hídricos eventuales aportados por chubascos excepcionales, que canalizados a través de barrancos, eran desviados por boqueras hasta los campos de cultivo, junto a la existencia de terrazas de cultivo escalonadas, impedían la arroyada rápida al provocar una derivación y posterior laminación de las aguas al pasar de unos bancales a otros (Morales et al., 1983). La principal causa del abandono de esta práctica ha sido la mejora de las técnicas de regadío y, sobre todo, el incremento de los caudales disponibles gracias a la llegada de agua procedente desde El Zarizejo (Villena), impulsado por la "Sociedad de Riegos de la Huerta de Alicante" en 1920, a los que hay que sumar la creación de pozos artesianos desde finales del siglo XIX. Con todas estas mejoras, progresivamente se iba transformando el secano tradicional en regadío. Estos nuevos aportes garantizaban un volumen de agua regular durante todo el año y no como ocurría con la práctica de boqueras que dependía de las irregulares precipitaciones de esta región. Otras causas de la desaparición de este sistema han sido el abandono de la actividad agraria debido a su escaso rendimiento y la urbanización del espacio rural.

Los beneficios que conllevaba la utilización de los aprovechamientos de turbias eran diversos. Por un lado se recargaban los acuíferos ya que se laminaban grandes extensiones de terreno, se incrementaba la productividad de los cultivos porque no sólo se aportaba un riego extra, sino que se creaba suelo y se fertilizaban los campos gracias a los aportes de limos, arcillas, etc. Además, ayudaba a la reducción 
de la erosión y facilitaba la retención de sedimentos, porque todo el espacio rural estaba estructurado mediante un complejo sistema de abancalamieto (márgenes, parats, sangradores, etc.) que impedían el arrastre y pérdida de suelo en éstas áreas. También, con la derivación de caudales, tanto de la escorrentía concentrada como difusa, se minimizaba el riesgo de inundación, pues gran parte del caudal circulante de las ramblas y vertientes causado por las precipitaciones intensas se repartía entre los cultivos, generando lo que se denomina comúnmente como inundación dirigida o provocada (Morales, 1969). De esta manera la agricultura tradicional mediante el aprovechamiento de escorrentías y la laminación de agua de los cauces, facilitaba un control exhaustivo de la torrencialidad y de los procesos de erosión hídrica.

Las construcciones asociadas a este sistema prácticamente han desaparecido durante la segunda mitad del siglo XX, pero también se ha extendido el desconocimiento de éstas por parte de la sociedad del sureste peninsular (Hernández y Moltó, 2010). Con el abandono de los aprovechamientos de turbias, las boqueras no sangran ya las crecidas y los arruinados caballones tampoco embalsan el agua ni detienen el arrastre del suelo, sometido en la actualidad a procesos de denudación y abarrancamiento muy activos (Gil, 1983). Con esta situación, los beneficios se han traducido en riesgos y problemáticas. Los espacios vuelven a su estado natural o pseudonatural, los bancales se erosionan, las laderas se desestabilizan, los parats, sangradores y márgenes desaparecen, etc.

También puede ocurrir que el sistema de boqueras aún este en funcionamiento, provocando inundaciones en las áreas que antiguamente eran espacios agrícolas y que en la actualidad se han convertido en urbanizaciones. Un ejemplo de ello es el gran número de antiguas boqueras que han sido sustituidas por caminos a lo largo de todo el término municipal, incluso muchas de ellas forman parte de parcelas urbanizadas (Urbanización Pozo San Antonio, El Sabinar -figura 12-, Vial de los Holandeses, urbanizaciones de la partida Canastell, etc.).

Figura 12. Boquera de ladera en pendiente utilizada como calle (El Sabinar).

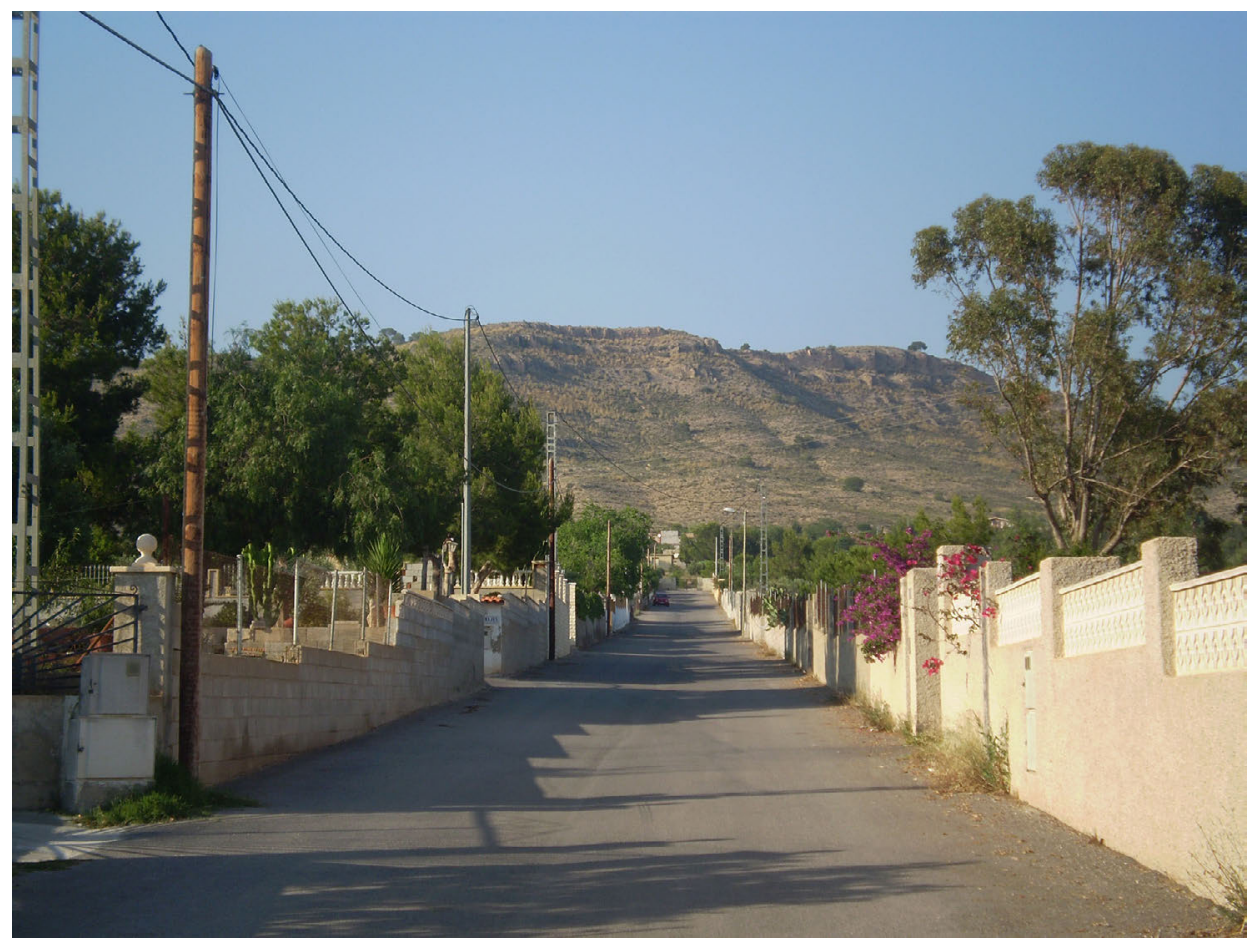

Las consecuencias de esta situación no sólo están presentes donde estos fenómenos se han desencadenado, sino también en las partes más bajas de las cuencas vertientes si tenemos en cuenta que es precisamente en este sector de la cuenca donde la ocupación humana, tanto núcleos de población como infraestructuras, alcanza mayor densidad (Hernández y Moltó, 2010). Un ejemplo de ello es la zona que se encuentra al sur del núcleo urbano conocida como el Plà de la Cova y donde en la actualidad se ubica la Universidad. Esta 
área es una zona endorreica donde tradicionalmente se irrigaba mediante la práctica de las boqueras, pero con la transformación de este espacio a principios del siglo XX con la instalación del Campo de Aviación, posteriormente en Cuartel y a finales de la década de 1960 en universidad, se ha desorganizado todo el antiguo espacio que era beneficiado con turbias. También hay que añadir la impermeabilización del suelo de esta zona y una serie de infraestructuras viales que se han construido alrededor de este recinto en una cota más alta, impidiendo la evacuación de la escorrentía y creando una zona de embalse cuando ocurren precipitaciones de intensidad horaria. Las últimas inundaciones que causaron graves problemas fueron las del 30 de Septiembre de 1997 donde se acumuló el caudal desbordado de la Rambla del Rambuchar y la escorrentía que descendía del núcleo urbano, anegando viales y los sótanos de los edificios de la universidad (figura 13).

Figura 13. Inundación de la Universidad de Alicante el 30 de Septiembre de 1997.

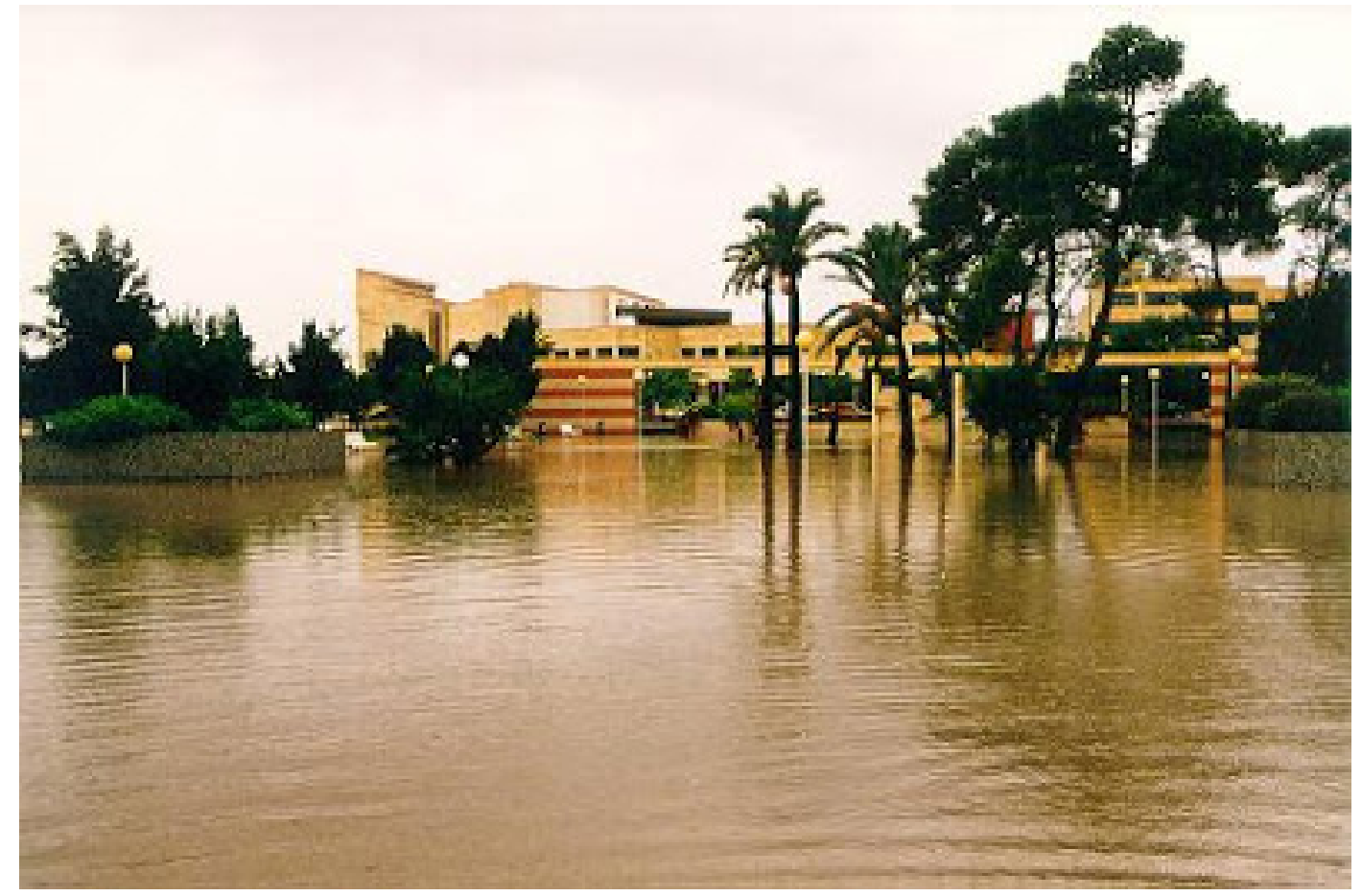

Fuente: http://www.alicantevivo.org/2007/10/nuestra-provincia-en-el-recuerdo-las.html

Ante esta situación se hace necesario actuar para intentar paliar estos problemas, al igual que su posible explotación, bien como recurso hídrico para abastecer la demanda de agua de servicios públicos o bien con finalidad ambiental. La utilización de las escorrentías ayudaría a minimizar los riesgos de inundación, a aumentar la recarga de acuíferos y reducir la presión sobre estos mediante su recolección para usos urbanos (baldeamiento de calles, jardínes, etc.). También se puede utilizar para regar cultivos como, por ejemplo, la actuación que llevó a cabo en 1983 la empresa agrícola Bonnysa restaurando la boquera de la Casa de Berenguer en la Rambla del Vergeret (cuenca del Montnegre) para almacenar el agua en una balsa de riego (Mondejar, 2003). Otro ejemplo es el caso de la actuación del IRYDA con la construcción en el Barranco del Vidre (Agost) de un dique conectado a una balsa de riego (Hernández, 2007).

Por último debemos mencionar que la degradación de los paisajes aterrazados y de este sistema conlleva una notable pérdida patrimonial, es decir, de elementos que reflejan las relaciones de una sociedad con el medio en el que se asienta y que son reflejo de su identidad (Hernández y Moltó, 2010). Por esta razón, parte de los aprovechamientos de turbias deberían explotarse como un recurso turístico-cultural, ya que asociados a estos sistemas aparecen un gran número de elementos patrimoniales de interés arquitectónico como, por ejemplo, las propias boqueras, los diques de derivación, balsas, aliviaderos, partidores, parats, sangradores, aljibes, masías, etc. 


\section{CONCLUSIONES}

En este estudio se ha analizado como era la práctica de los aprovechamientos de turbias en San Vicente del Raspeig. Era el único sistema existente para aportar agua a los cultivos de secano hasta la construcción de pozos artesianos de finales del siglo XIX y la llegada de caudales procedentes desde El Zarizejo de Villena en 1920. La práctica de boqueras entró en decadencia a partir del siglo XX como consecuencia de la aparición de nuevas y mejores técnicas de regadío y por el escaso rendimiento de la agricultura de secano en esta región. Este sistema dependía exclusivamente de las escorrentías de la lluvia, por lo tanto era un sistema muy condicionado al régimen de precipitaciones, ya que no todos los años se garantizaba el riego a los cultivos, pues si por algo se caracterizan las precipitaciones en esta región es por su irregularidad, tanto anual como interanual. La inexistencia de un curso fluvial permanente obligó a los antiguos pobladores a adoptar el sistema de boqueras como único recurso para poder obtener agua tanto para regar como para uso doméstico. Esta práctica ha estado presente en esta zona desde que el ser humano ocupó estas tierras ya que según diferentes hipótesis, el topónimo "El Raspeig" hace mención a "Ras de la peixera o pixera" (pixera es boquera en catalán) (Aura et al., 2006).

La superficie donde se practicaba el aprovechamiento de turbias podía ocupar aproximadamente el 40,52\% del total de la superficie cultivada, siendo regadas con escorrentía difusa el 19,26\% (597,11 ha.) y con escorrentía concentrada el 21,26\% (659,10 ha.). En relación con esta última, la superficie aproximada donde se practicaban boqueras con diques de derivación, en el caso de que el caudal recogido fuera importante, suponía el 51,12\% del total de la superficie regada con aprovechamiento de turbias y el 20,72\% del total de la superficie cultivada, ocupando una extensión aproximada de unas 642,30 ha. Cifras todas ellas que corroboran la importancia que este sistema tuvo en el agro de San Vicente de San Vicente del Raspeig.

Esta práctica era el único medio que tenían los agricultores para poder incrementar la productividad de sus cultivos (regar, crear nuevo suelo, fertilizar los campos, etc.,) hasta que se introdujeron nuevas técnicas. Además, el funcionamiento de este sistema garantizaba unos beneficios ambientales (reducción de la erosión y del caudal de avenida, buena gestión del territorio y de los recursos, etc.). Actualmente, con el abandono de los aprovechamientos de turbias, los beneficios se han traducido en problemáticas, como, por ejemplo, el aumento de la erosión, la degradación del paisaje y la acentuación de los riesgos de inundación, ya que la antigua superficie donde se llevaba a cabo este sistema se ha ocupado por suelos urbanos-residenciales.

\section{BIBLIOGRAFÍA}

ALBEROLA ROMÁ, A. (1984): Jurisdicción y Propiedad de la tierra en Alicante, siglos XVII Y XVIII. Alicante, Ayuntamiento de Alicante, 584 pp.

ALBEROLA ROMÁ, A. (1994): El pantano de Tibi y el sistema de riegos de la Huerta de Alicante. Alicante, Instituto Juan Gil-Albert, 194 pp.

AURA MURCiA, F; MiLláN LLÍN, V. y SANTACREU SOLER, J. M. (2006): Historia de San Vicente del Raspeig I. Desde los orígenes hasta la Primera República. Sant Vicent del Raspeig, Cercle d'Estudis Sequet però Sanet, Plec del Cercle n³1, 402 pp.

BOX AMORÓS, M. (1990): "Un ejemplo tardío de riego de boquera: La presa del Madroñal”, en Investigaciones Geográficas, nº 8 , pp. 51-57.

BOX AMORÓS, M. (1995): "Un aprovisionamiento tradicional de agua en el sureste ibérico: los aljibes", en Investigaciones Geográficas, nº13, pp. 91-106.

CANALS BEVIÁ, F. (2012): Historia Económica de Sant Vicent del Raspeig. Sant Vicent del Raspeig, Cercle d'Estudis Sequet però Senet, Plec del Cercle n57, 303 pp.

CAVANILlES, A. J. (1797): Observaciones sobre la Historia Natural, Geografía, Agricultura, Población y Frutos del Reyno de Valencia. Madrid, Imprenta Real.

CLIMENT i GINER, D. (1985): Les nostres plantes. Alicante, Instituto de Estudios Juan Gil-Albert, 312 pp. 
GIL MESEGUER, E. (2006): "Los paisajes agrarios de la Región de Murcia", en Papeles de Geografía, n43, pp. 19-30.

GIL MESEGUER, E.; PÉREZ MORALES, A. y GÓMEZ ESPÍN, J. Ma . (2012): "Precipitaciones y avenidas del 28-09-2012 en el cuadrante suroccidental de la Cuenca del Segura", en Papeles de Geografía, n55-56.

GIL OlCINA, A. (1971): El Campo de Lorca. Estudio de Geografía Agraria. Valencia, Departamento de Geografía, Instituto Juan Sebastián Elcano, 207 pp.

GIL OLCINA, A. (1975): "Embalses españoles de los siglos XVIII y XIX", en Estudios Geográficos, n¹29, pp. 557-596.

GIL OLCINA, A. (1983): "Lluvias excepcionales en la noche del 19 al 20 de Octubre de 1982 y riada en el Barranco de las Ovejas". Lluvias torrenciales e inundaciones en Alicante, Alicante, Instituto Universitario de Geografía, Universidad de Alicante, pp. 5-24.

GIL OLCINA A. (1993): La propiedad de aguas perennes en el sureste ibérico. Alicante, Universidad de Alicante, $370 \mathrm{pp}$.

GIL OLCINA, A. (2004): "Propiedad y subasta del agua en los ríos-ramblas murcianos". En: Gil Olcina, A. (eds): La cultura del agua en la Cuenca del Segura, pp.311-336.

GIL OlCINA, A. y RICO AMORÓS, A. M. (2007): El problema del agua en la Comunidad Valenciana. Fundación Agua y Progreso de la Comunidad Valenciana, 221 pp.

GÓMEZ ESPÍN, J. Ma (1996): "Abarán: cambios socioeconómicos y espaciales en el umbral del siglo XXI". Curso Abarán acercamiento a una realidad, Centro de Estudios Abaneros, pp. 103-130. El apartado 1.2. Un ejemplo de adaptación a las condiciones del territorio: los secanos mejorados con riego eventual de aguas de avenidas captadas mediante presas y boqueras, pp. 110-113.

GÓMEZ ESPÍN, J. Ma (2008): "Conflictos por el agua en Lorca y su comarca”, en Clavis, nº4-5, pp. 97-109.

GÓMEZ ESPÍN, J. Ma . y HERVÁS AVILÉS, R. Ma . (coords.) (2012): Patrimonio hidráulico y cultura del agua en el Mediterráneo. Murcia. Fundación Séneca. Regional Campus of Excellence "Campus Mare Nostrum”. Agencia Española de Cooperación Internacional para el Desarrollo, 287 pp.

GÓMEZ ESPÍN, J. Ma . y GIL MESEGUER, E. (2008): "Galerías y caños en el territorio de los Vélez (Almería)", en Revista velezana, $\mathrm{n}^{\circ} 27$, pp. 156-163.

GÓMEZ ESPÍN, J. Mª.; GIL MESEGUER, E.; ALIAGA SOLA, I.; LÓPEZ FERNÁNDEZ, J. A. y MARTÍNEZ MEDINA, R. (2007): "Las galerías, construcciones para alumbrar agua de freáticos próximos en el NE de la Región de Murcia: minados con espejuelos en Jumilla", en Investigaciones Geográficas, $\mathrm{n}^{\circ} 42$, pp. 89-107.

HERNÁNDEZ HERNÁNDEZ, M. (1994): Interpretación del paisaje agrario de la Toscana en el siglo XVIII. (Saggi di agricoltura). Instituto Universitario de Geografía. Universidad de Alicante, 120 pp.

HERNÁNDEZ HERNÁNDEZ, M. (1997): Paisajes agrarios y medio ambiente en Alicante. Evolución e impactos medioambientales en los paisajes agrarios alicantinos: 1959-1995. Alicante, Universidad de Alicante, $292 \mathrm{pp}$.

HERNÁNDEZ HERNÁNDEZ, M. (2010): "Terraced landscapes: new uses and dynamics", en III AngloSpanish Rural Geography Conference, pp.81-04.

HERNÁNDEZ HERNÁNDEZ, M. y MOLTÓ MANTERO, E. (2010): "La cultura del agua en ámbitos semiáridos: valores paisajísticos, ambientales y culturales", en Territorio, paisaje y territorio rural. XV Coloquio de Geografía Rural, Cáceres: Universidad de Extremadura, 398-409 pp.

JAVALOYES IVORRA, M.V. (2001): La agricultura y la gestión del agua en Sant Vicent del Raspeig. San Vicente del Raspeig, Ayuntamiento de San Vicente del Raspeig, 118 pp.

LÓPEZ CASTRO, J. L. (2003): "Baria y la agricultura fenicia en el extremo occidente", en Ecohistoria del Paisaje Agrario. La Agricultura fenicio-púnica en el Mediterráneo. Carlos Gómez Bellard, ed. Universidad de Valencia, pp. 93-110. 
LOPEZ GÓMEZ, A. (1951): "Riegos y cultivos en la Huerta de Alicante. Evolución y estado actual”, en Estudios Geográficos, n41, pp. 373-379.

LOPEZ GÓMEZ, A. (1973): "Presas del siglo XVIII y comienzos del XIX en Agost (Alicante)", en Cuadernos de Geografía, no13, pp. 1-3.

LOPEZ GÓMEZ, A. (1974): "El origen de los riegos valencianos. Los canales romanos”, en Cuadernos de Geografía, no15, pp. 1-24.

LOPEZ GÓMEZ, A. (1976): "Los riegos de avenida en la Huerta de Alicante. Evolución y estado actual", en Boletín de la Real Sociedad Geográfica, II, pp. 373-380.

LOPEZ GÓMEZ, A. (1996): Los embalses valencianos antiguos. Generalitat Valenciana, Conselleria de Obras Públicas, Urbanismo y Transporte, 92 pp.

MARCO MOLINA, J. A. y MORALES GIL, A. (1995): "Terrazas de cultivo abandonadas en el surestes peninsular: aspectos evolutivos", en Investigaciones Geográficas, n¹3, pp. 81-90.

MARCO MOLINA, J.A y VERA REBOLLO, J.F (1988): "Impactos de los usos del suelo y erosión en las cuencas vertientes del sur del País Valenciano", en Investigaciones Geográficas, nº, pp.7-32

MONDÉJAR SÁNCHEZ, J. M. (2003): La restauración de boqueras como modelo de gestión medioambiental en la Rambla del Vergeret. Prácticum de Licenciatura de Ciencias ambientales, Elche, Universidad Miguel Hernández.

MONDÉJAR SÁNCHEZ, J. M. (2009): El riego de boqueras: una técnica hidráulica para la gestión ambiental de territorios semiáridos y lucha contra la desertificación. Aprovechamientos tradicionales de aguas de escorrentía en las cuencas de la comarca de l'Alacantí. Tesis Doctoral. Inédita, 2 volúmenes.

MORALES GIL, A. (1969): "El riego con agua de avenida en las laderas subáridas", en Papeles del departamento de Geografía, nº 1, Murcia, pp. 167-183.

MORALES GIL, A. y BOX AMORÓS, M. (1986): "El aprovechamiento del agua y los suelos en un dominio semiárido: la cuenca del Barranco Blanco.Agost”, en Investigaciones Geográficas, n4, pp. 7-24.

MORALES GIL, A. y BOX AMORÓS, M. (1996): "Boqueras y Azudes: el aprovechamiento exhaustivo de las aguas esporádicas en el sureste peninsular". En: Cuatro siglos de técnicas hidráulicas en tierras alicantinas. Instituto de Cultura "Juan Gil-Albert", Diputación Provincial de Alicante, pp. 31-41.

MORALES GIL, A. y BRU RONDA, C. (1984): "Disponibilidades hídricas y modernas técnicas de embalse en el Campo de Alicante", en Investigaciones Geográficas, n², pp. 19-51.

MORALES GIL, A.; BOX AMORÓS, M. y MARCO MOLINA, J. A. (1989): "El aprovechamiento de las aguas de avenida: Derecho consuetudinario y disposiciones legales". En: Avenidas fluviales e inundaciones en la cuenca del mediterráneo. Instituto Universitario de Geografía de la Universidad de Alicante. Caja de Ahorros del Mediterráneo, pp. 553-563.

MORALES GIL, A.; BOX AMORÓS, M. y MARCO MOLINA, J.A. (1991): "El medio físico y la presa del Román (Jumilla): un emplazamiento favorable”, en Investigaciones Geográficas, n9, pp.69-80.

MORALES GIL, A.; BRU RONDA, C. y BOX AMORÓS, M. (1983): “Condiciones morfológicas y chubascos de fuerte intensidad horaria en la cuenca vertiente del Barranco de las Ovejas (Alicante)". Lluvias torrenciales e inundaciones en Alicante, Instituto Universitario de Geografía, Universidad de Alicante, Alicante, pp. 25-72.

MORATAlla JÁVEGA, J. (2000): Arqueología y Patrimonio Histórico en Sant Vicent del Raspeig. San Vicente del Raspeig, Cuaderns de El Raspeig Nº 1,208 pp.

PÉREZ MORALES, A. (2010): “Actuaciones de carácter estructural para la mitigación y prevención de los efectos de las riadas e inundaciones en los municipios del sur de la Región de Murcia”, en Boletín de la Asociación de Geógrafos Españoles, n53, pp. 267-285. 